ANUARIO DE Estudios Medievales 51/1, enero-junio de 2021, pp. 339-372

ISSN 0066-5061

https://doi.org/10.3989/aem.2021.51.1.11

\title{
LA PROMOCIÓN ARTÍSTICA DEL ARZOBISPO COMPOSTELANO DON LOPE DE MENDOZA: DEVOCIÓN, CULTO Y ESTRATEGIA EN EL ÁMBITO ATLÁNTICO
}

\author{
THE ARTISTIC PATRONAGE OF THE ARCHBISHOP OF COMPOSTELA \\ DON LOPE DE MENDOZA: DEVOTION, WORSHIP AND STRATEGY \\ IN THE ATLANTIC AREA
}

\author{
MARTA CENDÓN FERNÁNDEZ \\ Universidad de Santiago de Compostela \\ https://orcid.org/0000-0002-5975-4910 \\ DAVID CHAO CASTRO \\ Universidad de Santiago de Compostela \\ https://orcid.org/0000-0002-0654-7475
}

\begin{abstract}
Resumen: En el presente trabajo se estudia la promoción artística del arzobispo don Lope de Mendoza (1400-1445) en dos de las villas costeras más destacadas de la Tierra de Santiago: Muros y Noia. Se ha dejado de lado el patronazgo episcopal en la propia Compostela y Padrón por haber sido tratado por la historiografía, optando por abordar conjuntos monumentales que sirvieron al prelado como refrendo del apoyo prestado a los florecientes puertos arzobispales y nuevos linajes urbanos que ocupaban sus oficios concejiles, así como su amparo y cuidado de los peregrinos al sepulcro apostólico. Pero ante todo el análisis planteado desde esta óptica hacia ejemplos tan destacados como Santa María do Campo de Muros o San Martín de Noia nos permite obtener esa pretendida imagen del poder, prestigio y sentido piadoso del que pasa por ser uno de los mitrados más destacados de la Baja Edad Media compostelana e hispana.
\end{abstract}

Palabras clave: Lope de Mendoza; Muros; Noia; devoción jacobea.

Abstract: This article studies the artistic works promoted by Archbishop Lope de Mendoza (14001445 ) in two of the most outstanding coastal towns in the Santiago region: Muros and Noia. Episcopal patronage in Compostela itself and Padrón has been omitted because it has been covered by previous historical studies. We have thus chosen to consider these monumental ensembles, which served the prelate as an endorsement of the support given to the flourishing archiepiscopal ports and new urban lineages who occupied their council offices, as well as their protection and care for pilgrims to the apostolic tomb. But above all, the analysis proposed from this point of view of such outstanding examples of ecclesiastical architecture as Santa María do Campo de Muros or San Martín de Noia allows us to obtain the image of the power, prestige and pious sense that was sought by one of the most prominent late medieval archbishops of Compostela and the Spanish Kingdoms.

Keywords: Lope de Mendoza; Muros; Noia; devotion to Saint James.

\section{SUMARIO}

1. Introducción.- 2. Santa María do Campo de Muros: una nueva iglesia parroquial.3. San Martín de Noia: una "catedral" jacobea en la costa.- 4. Conclusiones.- 5. Bibliografía citada.

Citation / Cómo citar este artículo: Cendón Fernández, Marta; Chao Castro, David (2021), La promoción artística del arzobispo compostelano don Lope de Mendoza: devoción, culto y estrategia en el ámbito atlántico, "Anuario de Estudios Medievales" 51/1, pp. 339-372. https://doi.org/10.3989/aem.2021.51.1.11

Copyright: (C) 2021 CSIC. Este es un artículo de acceso abierto distribuido bajo los términos de la licencia de uso y distribución Creative Commons Reconocimiento 4.0 Internacional (CC BY 4.0). 


\section{INTRODUCCIÓN}

Don Lope de Mendoza, hijo de Juan Fernández de Mendoza, Alcalde Mayor de Sevilla, y de Leonor Alonso de Saavedra ${ }^{1}$, pertenece a una familia importante pues su padre era hijo de Fernando Mate de Luna y Mayor de Mendoza, que ocupó cargos de relevancia en esa ciudad ${ }^{2}$. Prebendado en Sevilla, fue promovido para la sede de Mondoñedo el 16 de junio de 1393. Con posterioridad al 18 de enero de 1399 fue trasladado a Santiago, tras la huida de su predecesor, Juan García Manrique. Al mismo tiempo que ocupaba la sede compostelana fue administrador apostólico de Osma (entre 1404 y 1408).

En su diócesis desarrolló una estrategia orientada en tres direcciones: el reforzamiento del poder arzobispal frente a la nobleza y los ciudadanos; el impulso de los puertos y villas costeras; y la potenciación de la devoción jacobea y atención a los peregrinos. Es en torno a estos tres ejes el modo en el que vamos a llevar a cabo el análisis de su promoción artística, obviando el estudio de las obras que financia en Santiago de Compostela, que han sido ya objeto de otros trabajos de investigación ${ }^{3}$, para centrarnos en su intervención en las villas costeras: Muros y Noia.

Para reforzar su poder, don Lope se rodeó de miembros de su familia, lo que permitió que una parte de la nobleza sevillana se asentase en Galicia. A su hermano Juan de Mendoza lo nombra Pertiguero Mayor de la Iglesia de Santiago en $1400^{4}$, su representante en los asuntos temporales; sitúa a su sobrino Pedro Fernández de Mendoza como Arcediano de Trastámara ${ }^{5}$ y al morir don Fadrique, Alonso de Mendoza es Pertiguero Mayor. Pero no solo los sitúa en puestos de poder, sino que también procura el establecimiento de relaciones con la nobleza local por vía matrimonial que, si en unos casos no facilitan la concordia, en otros lo dotan de aliados. A su vez encontramos la presencia de miembros de su linaje en numerosas iglesias, en las que está

1 “Juan Fernandez de Mendoza, Alcalde mayor de Sevilla, hermano mayor de Fernán Ibañez, hallóse en todas las empresas de su tiempo como bizarro caballero. Fue Embaxador del Rey Don Alonso á los Reyes de Francia é Inglaterra, en compañía de Don Diego Ramírez de Guzman (...); de Doña Leonor Alonso de Saavedra su mujer tuvo gran número de hijos ilustres, Fernán Yañez de Mendoza, y Diego Fernandez de Mendoza, Alcaldes mayores de Sevilla, Juan Fernandez de Mendoza, Abad mayor de ella, y el esclarecido Don Lope de Mendoza, Arzobispo de Santiago", Ortiz 1795, p. 122. Es erróneo el dato que proporcionaba Gil y González Dávila quien indicaba como padre a Pedro Mate de Luna, González 1645, p.74.

${ }^{2}$ Hijo del Almirante Juan Mate de Luna, fallecido el 9 de agosto de 1299, Ortiz 1795 , pp. 16-17, 122; Flórez 1764, pp. 186-187.

${ }^{3}$ Caamaño 1960; Cendón 1996; Cendón, Barral, Fraga 2000; Fernández 2005; Yzquierdo 2006-2007; Cendón, Chao 2014.

${ }^{4}$ López 1895, vol. II, p. 37; Caamaño 1960, p. 25.

${ }^{5}$ Ortiz 1795, p. 334. 
presente su emblema heráldico: las armas de los Maté de Luna, trasplantadas a Galicia por nuestro arzobispo, si bien después - a comienzos del XVI- adoptaron el cuartelado en aspa traído por la rama más destacada de los Mendoza -titular de la Casa del Infantado-, que no les correspondía ${ }^{6}$.

\section{SANTA MARÍA do CAMPo DE Muros: unA NUEVA IGLESIA PARROQUiAL}

En los inicios de la Baja Edad Media, Muros era una reducida villa de realengo, debida a Alfonso IX. El interés de este monarca y el de sus sucesores por la población de Muros quizás respondiese al deseo de contrarrestar el protagonismo urbano de la cercana villa de Noia, de señorío arzobispal ${ }^{7}$. Este proyecto municipalista de la Corona castellana se incrementaría con el paso de los años, concretándose en la Carta de Población otorgada por Sancho IV el 4 de octubre de 12836, fundamentada en el Fuero de Benavente, aunque no sabemos si dicha iniciativa regia fue causa o consecuencia del crecimiento poblacional y la importancia mercantil y pesquera que la Corona deseaba para Muros y demás concejos de realengo insertos en la Tierra de Santiago ${ }^{8}$.

A la manera de la cercana Noia -su principal rival en la actividad pesquera, que no en la mercantil, donde ambas cooperaban de manera habitual ${ }^{9}-$, Muros también fue aglutinando en su ámbito inmediato la venta del pescado, como puerto pesquero de referencia para el entorno, la actividad artesanal y la comercial, con la celebración del mercado dominical; por consiguiente, sería el núcleo poblacional que en un futuro albergaría la corporación municipal y al notario ${ }^{10}$. El temor a que Muros pudiese llegar a competir con Noia en la misma ría llevaría a los arzobispos compostelanos a intentar hacerse con su señorío, consiguiéndolo don Rodrigo González en un momento de debilidad de la Corona durante el valimiento de doña María de Molina: el 8 de agosto de 1299 era firmado el paso de la villa de Muros con su alfoz a la Iglesia de Santiago ${ }^{11}$, confirmándolo Fernando IV el 17 de diciembre de 1309.

${ }^{6}$ Pardo de Guevara 2012, p. 118.

${ }^{7}$ García 1987, vol. II, p. 183.

${ }^{8}$ Análisis de la realidad histórica de Muros en Ibidem, pp. 183-186.

${ }^{9}$ Ferreira 1988, p. 96.

${ }^{10}$ Ibidem, pp. 89-91. García Oro señala que en 1307 Muros tendría reducidas dimensiones, sin murallas y con la única presencia de su "torre", sin apenas organización municipal; y esta situación poco mudaría a lo largo del siglo XIV. Además, en 1389 se produjo un grave ataque a manos de las tropas del nuevo rey portugués João I de Avis, que obligó a la restauración por parte del arzobispo García Manrique, que inicia la construcción de una çerca y ofrece praças a los que quisiesen edificar su nueva casa en la afectada Muros, García 1987, vol. II, pp. 186-187.

${ }^{11}$ Texto en López 1904, pp. 528-529. Este privilegio era confirmado el 17 de diciembre de 1309 por el propio Fernando IV, Ibidem, p. 529. 
En todo caso, ya desde 1299 tanto el arzobispo como el propio cabildo de Santiago debían de tener derechos y compartir privilegios sobre la villa. Pero en 1321 Berenguel de Landoria se hizo para la Mitra con todo el señorío de Muros por cambio que dou o arçobispo a o cabidoo ${ }^{12}$. Por tanto, es preciso reconocer en esta iniciativa arzobispal el punto de partida de lo que va a ser un programa de promoción de las principales villas costeras de la Tierra de Santiago, con evidentes intereses comerciales, en aras a promover las actividades mercantiles en villas como Coruña, Pontevedra, Noia o Padrón, y a servir también de puerto para el desembarco de peregrinos con destino al santuario apostólico. Y si don Berenguel fue el gestor e impulsor de semejante empresa promocional, cabe otorgarle a don Lope de Mendoza el papel de reactivador definitivo de dicha iniciativa arzobispal.

La intensa actividad promotora desarrollada por don Lope de Mendoza a lo largo de su dilatada prelatura tiene, fuera de Santiago, una de sus primeras manifestaciones monumentales en la villa de Muros. Así, ya en el primer año de su pontificado visita Muros y atiende a sus intereses ${ }^{13}$; vería entonces la opción de aprovechar los inicios de la construcción de la nueva iglesia parroquial de la villa, más céntrica y dentro de los límites de la cerca, pues la antigua parroquial de San Pedro quedaba fuera y un tanto lejos ${ }^{14}$. Señala García Oro que por entonces el coro de este nuevo edificio eclesial -Santa María do Campo- ya estaba en construcción, en concreto en 1402, con un aporte documental en el período 1402-1406 muy clarificador: los vecinos recurrieron al nuevo arzobispo, su señor, para que les condonase los diezmos atrasados y los destinase a la edificación de este nuevo templo; que les concediese indulgencias; que les permitiese efectuar colectas tanto dentro como fuera de la iglesia parroquial; que pudiesen destinar a la construcción aquellas heredades que habían quedado sin propietario; y que designase un procurador para impulsar y supervisar con eficacia la obra ${ }^{15}$.

Don Lope se prestó a satisfacer todas estas demandas (fijando las debidas cautelas en la delimitación de las heredades señaladas), así como la otra gran solicitud de autorización arzobispal para la construcción y gestión de una carnicería dentro de la villa, lo que permitió señalar comisiones para am-

${ }_{12}$ Ibidem, p. 52; Artaza 1959, vol. I, pp. 213-214. Sobre las rentas percibidas por el arzobispado de Santiago en Muros, López 1914, p. 531 y García 1987, vol. II, p.186.

${ }^{13}$ López 1904, pp. 61-62.

${ }^{14}$ García 1987, vol. II, p. 187.

${ }^{15}$ Ibidem, pp. 187-188, se hace eco de la especial querencia de don Lope de Mendoza por las órdenes mendicantes, en especial los franciscanos, pues pide que encargue su predicación a fray Rodrigo de Moraña, prohibiendo a otros, frailes o clérigos, frailes o clérigos, que prediquen en Muros, salvo en Cuaresma y Adviento. 
bas empresas y ponerlas en marcha en agosto de $1402^{16}$. Fue nombrado como nuevo procurador de la obra de la iglesia el notario Lourenço Affonso, a buen seguro familiar directo del Lopo Affonso en quien recayó el arriendo de la nueva carnicería tras la correspondiente puja pública, por 12.000 maravedíes, que daría dineros para proseguir las obras del nuevo templo ${ }^{17}$.

Los Affonso o Alfonso fueron una estirpe hidalga vinculada a las villas de Muros y Noia desde inicios del siglo XIV ${ }^{18}$. En el caso muradano, pudieron ejercer quizás en exclusiva la función notarial de la villa, con la figura destacada, en el último tercio, de don Lorenzo Alfonso ${ }^{19}$, quien otorgaba su testamento el 4 de junio de $1404^{20}$. Ha de tenerse en cuenta que en mayo de 1406 don Lope de Mendoza comparecía personalmente en la villa para organizar un renovado régimen municipal y designar a sus oficiales, entre ellos Lorenzo Affonso y Lope Affonso como regidores por tiempo indefinido ${ }^{21}$.

Todos estos apuntes nos permiten comprender mejor la inscripción que figura rodeando el arco labrado en el dintel exterior de la puerta norte de la iglesia de Santa María do Campo:

$\dagger$ : : ARÇIB(IS)PO : DON : LOPO : A : MANDOU : FAZER : ET

: FEZO : MOI/TAS : GRAÇAS : O CONCEL(L)O : DE : MURO

: ACABOU : L. $^{\text {co A }} .^{\circ}: \mathrm{A}:$ COMENÇOU : E : PROCUROU : SUB

: ANNO : $\mathrm{M}: \mathrm{CCCC}^{22}$.

Simplemente habría que añadir a los anteriores un último protagonista: el deán don Diego de Muros, quien logra que esta iglesia sea elevada a la dignidad de colegiata en 1500, por concesión del papa Alejandro VI ${ }^{23}$.

La planta de Santa María do Campo de Muros (fig. 1) conserva su ábside cuadrangular, orientado canónicamente y cubierto por una bóveda de

${ }^{16}$ Ibidem, p. 188.

${ }^{17}$ Ibidem.

${ }^{18}$ Ibidem, p. 278.

${ }^{19}$ Los Affonso se mantuvieron desde el siglo XIV como notarios de Muros. Para el cuerpo de regidores municipales creado por el arzobispo en 1406, designó a Lope Affonso y Lorenzo Affonso, cuerpo casi monopolizado por este linaje tan próximo al prelado, Artaza 1959, p. 215. Al morir Lorenzo dejaría como sucesores de sus bienes y puesto a Ruy Pérez y a Gómez Alfonso; este último, notario en la villa desde las primeras décadas del siglo $\mathrm{XV}$, emparentaría con otra estirpe destacada de la hidalguía muradana: los Rodríguez de Muros. A su vez Gómez Alfonso recibió otros bienes procedentes de los Alfonso de Noia (en concreto de Fernán Alfonso da Corredoira), que demuestra el vínculo de parentesco que unía a ambas ramas en un extremo y otro de la ría, López 1914, passim y García 1987, vol. II, pp. 277-279.

${ }^{20}$ Artaza 1959, pp. 124-127.

${ }^{21}$ García 1987, vol. II, pp. 190-193.

${ }^{22}$ Transcripción reelaborada a partir de la de López 1904, p. 62; Yzquierdo 2006-2007, p. 118.

${ }^{23}$ Caamaño 1962, p. 120. 
crucería cuatripartita cuyos nervios apean en dos capiteles sobre columnas acodilladas (parte oriental) y en sendas ménsulas embutidas al lado de los capiteles del arco triunfal, coincidiendo los nervios en una clave de sencilla decoración vegetal. Destaca en su testero la apertura de una única ventana central de arco apuntado que, aunque ligeramente alterada en su exterior, sobre todo en la chambrana, muestra las mismas características que se aprecian en los escasos restos de ventanas que se conservan en los muros laterales de la nave ${ }^{24}$. También en este mismo testero, en su parte exterior, se aprecia la existencia de restos de una serie de ménsulas dispuestas alrededor de dicha ventana central, que parecen demostrar la existencia de una estructura, hoy perdida, a modo de pequeño pórtico o gran baldaquino, que tal vez habría que poner en relación con prácticas cultuales relacionadas con la advocación mariana del templo.

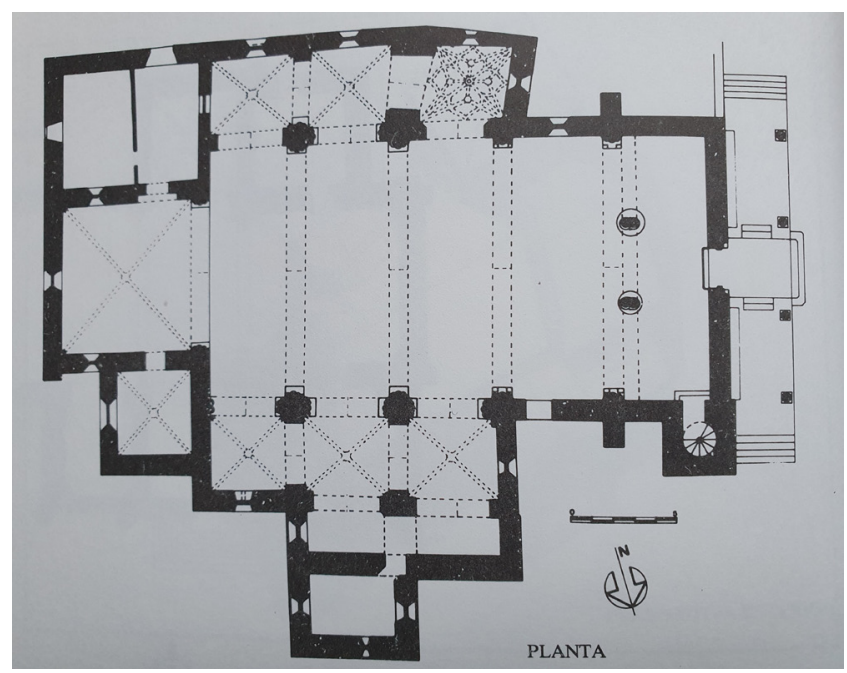

Fig. 1. Santa María do Campo de Muros. Planta (Arquitectura gótica en Galicia. Los templos: catálogo gráfico (1986), Santiago de Compostela, COAG Universidad de Santiago de Compostela, p. 98).

Existen dos elementos vinculados a esta capilla mayor que han de ser reseñados. En primer lugar, el par de arcosolios que se abren en el muro interior del lado de la epístola, de los cuales el oriental conserva el sepulcro de Lorenzo Affonso, mientras el otro aparece vacío, debido a que fue abierto un vano de comunicación con una nueva edificación levantada al lado sur de dicho ábside. Por su parte, el sepulcro de Lorenzo Affonso (fig. 2) consta de una tapa,

${ }^{24}$ Dicha ventana muestra la influencia de la arquitectura mendicante, Fernández 1998, p. 714. 
con una inscripción identificativa en caracteres góticos grabada en su vertiente inclinada exterior: Aquí iaz Lourenço Alfonso iurado de Muro e finou a XV de ianeiro de $M C C C C X I^{25}$. El frontal de la yacija muestra la imagen en bajorrelieve del jurado de Muros y procurador de la obra de la iglesia, en cuya representación se ha querido insistir en su condición de alto oficial municipal y notario mediante sus ropajes: largo ropón con pliegues paralelos y simétricos, abotonado en la parte central, mientras una capa corta protege los hombros y se abre para permitir que el yacente muestre un gesto de oración perpetua mediante las manos juntas sobre el pecho; su cabeza, bastante deteriorada, ofrece los restos de lo que debió de ser un bonete de tipo gallonado alusivo a su categoría profesional y social, enmarcada dicha cabeza por un arco trilobulado con rosetas en las esquinas, inscrito en un arco apuntado.

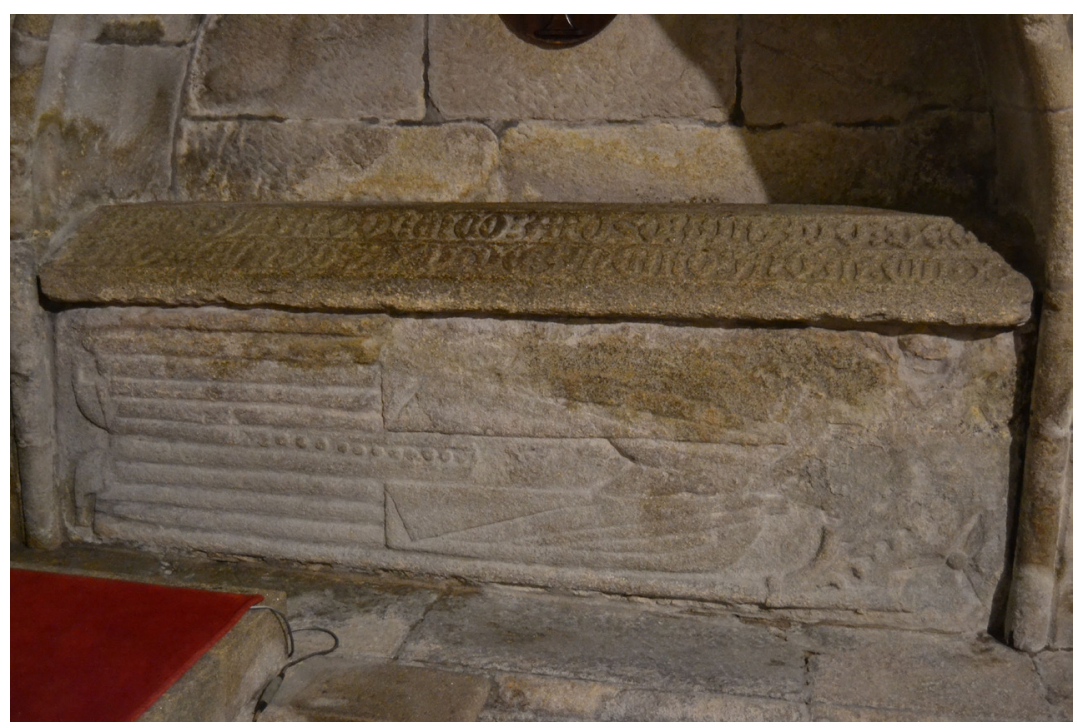

Fig. 2. Santa María do Campo de Muros. Sepulcro de Lorenzo Affonso en el lado de la epístola de la capilla mayor. Foto de los autores.

Por otro lado, es preciso señalar la disposición en el muro exterior norte de la sacristía, adosada a dicho ábside, de una labra heráldica con las armas de don Lope de Mendoza: un menguante jaquelado con una bordura con roeles de veros. Dicho escudo ha pasado desapercibido para la historiografía dedicada a esta iglesia ${ }^{26}$, y cabe suponer que su ubicación en una edifi-

${ }^{25}$ Caamaño 1960, pp. 50-51.

${ }^{26}$ La menciona de pasada Caamaño 1962, p. 121. 
cación adosada a posteriori al presbiterio, podría haber sido consecuencia de su reubicación tras dicha anexión.

La existencia de estos arcosolios interiores en la costanera sur del ábside, donde uno de ellos sigue cobijando el sepulcro de Lorenzo Affonso, obliga a abundar en el papel que dicho personaje hubo de desempeñar en la construcción de la iglesia. Porque el hecho de ejercer un probable patronazgo sobre esta capilla mayor-lo que se deduce de este mismo panteón, en la búsqueda de la proximidad a la presencia viva de Cristo redentor en la Eucaristía- vendría a ratificar ese inicio de las obras anterior al compromiso de don Lope de Mendoza con la misma a partir de 1402 y, por lo mismo, a una promoción directa por parte de don Lorenzo de la nueva iglesia parroquial en sus inicios en 1400, conforme figura en la inscripción de la puerta norte. Aun cuando la capilla mayor ya estuviese comprometida para servir como morada última de don Lorenzo, y quizás también de algún otro familiar inmediato, lo cierto es que solo tras la financiación asegurada merced a las donaciones y derechos cedidos por don Lope de Mendoza para la empresa, habría sido posible que la fábrica avanzase a buen ritmo a partir de $1402^{27}$. Se comenzaría entonces con el remate del propio ábside, para continuar con la nave única, desarrollada con un ambicioso plan en cuanto a sus amplias dimensiones.

Dicha nave está dividida en 5 tramos por medio de grandes arcos perpiaños que sirven de sujeción a la cubierta de madera (fig. 3). Estos arcos doblados y apuntados, de perfil rectangular, con arista achaflanada en nacela y baquetonados en su dobladura ${ }^{28}$, semejan replicar el arco triunfal, demostrando el sentido unitario de la fábrica y sugiriendo un avance relativamente rápido de las obras. Se apoyan estos arcos en haces de tres semicolumnas sobre basas áticas y altos plintos ${ }^{29}$, con capiteles vegetales y alguno figurativo, que tendrían -y mantienen en varios casos- su correspondiente contrafuerte exterior de notable proyección. Dichos soportes interiores son relativamente bajos, lo que no impide que los arcos perpiaños alcancen una destacada altura en la dobladura central, aun cuando su apuntamiento no es excesivamente marcado. Ya en el exterior, los muros laterales terminarían en una cornisa sobre canecillos poco volados, decorados con formas vegetales, geométricas y figurativas, que en ciertas partes se han conservado.

${ }^{27}$ Sobre la búsqueda de espacios privilegiados como lugar de sepultura y su relación con la promoción artística véase Yarza 1988, pp. 67-91; Bango 1992, pp. 93-132; Carrero 1999, pp. 149-175; Alonso, Martínez de Aguirre 2011, pp. 103-147; Carrero 2011, pp. 115-129; Teijeira, Herráez, Cosmen 2014; Español 2015, pp. 93-120; Herráez, Cosmen, Teijeira, Moráis 2018; Escandell, Boto, Lozano 2019.

${ }^{28}$ Para el estudio de esta tipología de arcos, Caamaño 1962, p. 41.

${ }^{29}$ Este tipo de soportes resultaría habitual para las iglesias del "gótico marinero", como se puede ver también en el coetáneo templo de San Marcos de Corcubión, rompiendo con la tradición anterior de soportes inspirados en las soluciones mendicantes, Yzquierdo, Manso 1996, p. 326. 


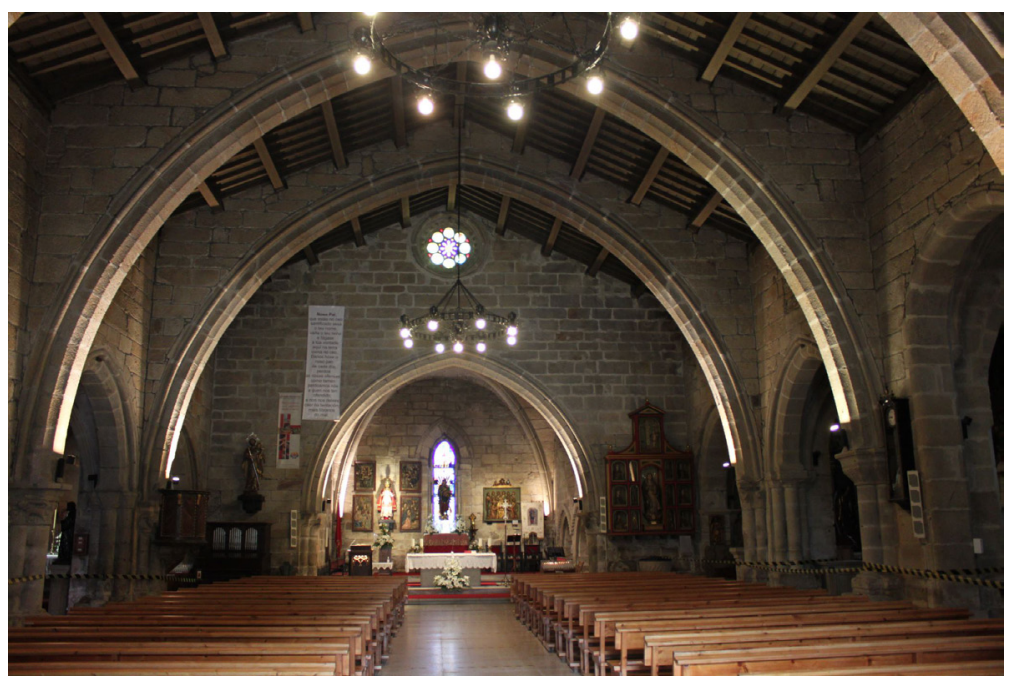

Fig. 3. Santa María do Campo de Muros. Interior de la nave hacia la capilla mayor.

Foto de los autores.

Se ha señalado acertadamente a la iglesia de Santa María a Nova de Noia como influencia directa para esta estructura muradana ${ }^{30}$. Esto vendría a delatar tanto el papel como modelo que habría desempeñado la pujante villa de Noia de cara a los anhelos de Muros, como desde el punto de vista arzobispal el ejemplo de Berenguel de Landoria -patrocinador de la iglesia noiesacon respecto a don Lope de Mendoza. Estamos ante ejemplos propios del denominado por Caamaño como "gótico marinero" 31 , donde la iglesia de Muros se inscribiría en la segunda fase definida por este historiador $(1350-1450)^{32}$. Y a su vez Muros pudo haber servido, ya en el avance de su construcción, como referente a tener en cuenta, junto con la propia iglesia de Santa María a Nova, para la construcción de la gran nave de San Martín de Noia que impulsa asimismo don Lope de Mendoza.

La presencia en la fachada occidental de un gran rosetón (fig. 4) cuya ornamentación con puntas de diamante recuerda la decoración del trasdós de

${ }^{30}$ Caamaño 1962, p.121.

${ }^{31}$ Ibidem, pp. 19-20. La denominación "gótico marinero" obedece a una ubicación prioritaria de estas iglesias en zonas costeras, donde el comercio marítimo y la pesca constituían su principal actividad económica. En líneas generales se caracterizan por poseer una amplia nave única con cubierta de madera sostenida por arcos perpiaños apuntados, que arrancan de semicolumnas o pilastras, a modo de contrafuertes interiores, así como una cabecera abovedada, habitualmente cuadrangular o hemipoligonal.

${ }^{32}$ Ibidem, p. 20; Manso 1996, pp. 321-327. 
los arcosolios del presbiterio, y sobre todo la presencia de otras dos labras heráldicas con las mismas armas de don Lope en el exterior de dicha fachada -una en la parte superior derecha de la puerta principal ${ }^{33}$ y otra encima del rosetón-, hacen pensar en un remate de la obra todavía en tiempos de dicho prelado $^{34}$; la inclusión también de bolas ornamentales en este rosetón se observa en los enmarques del rosetón occidental de San Martín de Noia, promovido por el mismo prelado. En este sentido creemos que la inscripción de la puerta norte no pierde sentido, puesto que aunque señala que el Concello de Muros remató la fábrica, dicho cometido pudo ser llevado a buen término por las moitas graças concedidas al municipio por don Lope.

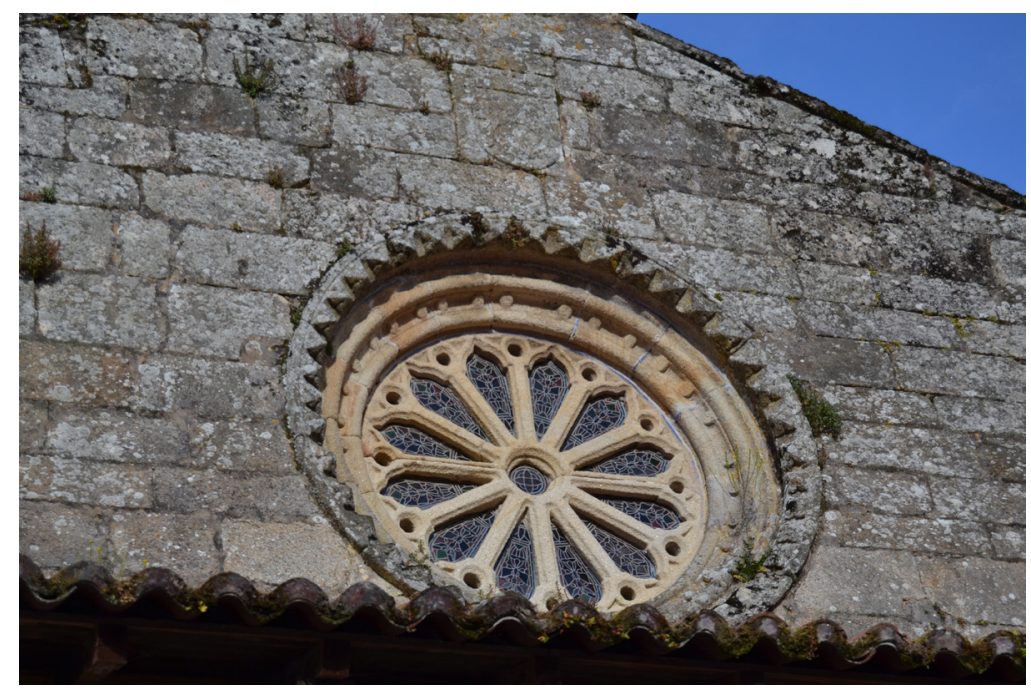

Fig. 4. Santa María do Campo de Muros. Rosetón en la fachada occidental. Foto de los autores.

${ }^{33}$ Resulta llamativa la ausencia de labra heráldica al otro lado de la puerta, para guardar la simetría, pero se conserva allí un sillar vertical, tan erosionado como la mayor parte de los sillares de la mitad inferior de esta fachada -que contrasta con la buena conservación del escudo mencionado al otro lado del vano-, y con idénticas dimensiones al del que acoge las armas de don Lope: o fue repicado o fue extraído y en su lugar colocado dicho sillar. En todo caso, cabe pensar en un planteamiento simétrico de las armas del prelado, parecido al que se verá en el dintel de la portada occidental de San Martín de Noia.

${ }^{34} \mathrm{El}$ desgaste que muestra la piedra en la mitad inferior porticada de esta fachada occidental, así como la estructura tan simple de su portada, igualmente desgastada, ha llevado a plantear la posibilidad de un reaprovechamiento de las piezas de una antigua portada tardorrománica, incluso identificándola con la de un supuesto monasterio de monjas que según Jerónimo del Hoyo se levantaba en el mismo solar antes del ataque portugués, Del Hoyo 1952, p. 330. 
Por tanto, cabe pensar que la iglesia de Santa María do Campo de Muros pudo ser concluida -en su proyecto inicial- en tiempos de Mendoza, esto es, antes de 1445. Dicha cronología para la capilla mayor y la nave coincide con los estudios llevados a cabo por Fernández Rodríguez, a partir de los cuales llega a considerar la realización de la cabecera y nave por parte de un único taller vinculado a los prototipos desarrollados por los denominados por Manso como "talleres lucenses", aunque no de manera directa, sino a través del tamiz de otros talleres derivados de los primeros que desde fines del siglo XIV intervienen en las grandes fábricas de Betanzos - conformando unos "talleres brigantinos" específicos-; y desde donde se trasladan para participar en los templos mendicantes coruñeses ${ }^{35}$. Estilísticamente el sepulcro de don Lorenzo Alfonso también se ha de poner en relación con los mismos talleres brigantinos-coruñeses ${ }^{36}$.

Bien es cierto que, a la vista de la iglesia actual, tan pronto como se remató el templo en su plan inicial debió de sufrir las primeras modificaciones. Así, cabe pensar que ya en la segunda mitad del siglo XV pudo haber sido añadida la sacristía en el lado septentrional de su cabecera ${ }^{37}$, y posiblemente también las capillas laterales abiertas al primer tramo de la nave (tanto del lado del evangelio como de la epístola) $)^{38}$, ambas concebidas como capillas funerarias, con arcosolios -actualmente vacíos- en sus testeros; y ya hacia fines de dicho siglo también el par de capillas siguiente ${ }^{39}$. Asimismo, en estas mismas fechas, aunque en este caso con la certeza del intervalo cronológico 1450-1460, era edificado el coro alto a los pies de la nave; precisamente en su parte occidental -para que sean visibles al acceder a la iglesia por su portada principal- se disponen sendas labras heráldicas con las armas del arzobispo Rodrigo de Luna, lo que indica su participación en la promoción de construcciones en Santa María do Campo como pueda ser este coro alto ${ }^{40}$. Con ello se

\footnotetext{
${ }^{35}$ Fernández 1998, pp. 753-754; Manso 1993, pp. 101-102 y ss.

${ }^{36}$ Fernández 1998, pp. 748-750; Manso 1993, pp. 453-462.

${ }^{37}$ Fernández 1998, p. 676.

${ }^{38} \mathrm{Al}$ analizar la sacristía y las capillas laterales se aprecia cómo fueron adosadas a los contrafuertes exteriores, al tiempo que su apertura hacia la nave afectó a las antiguas ventanas. Para las advocaciones de las capillas, Artaza 1922, p. 158; 1959, passim; Caamaño 1962, pp. 117-119; Fernández 1998, pp. 678 y ss.

${ }_{39}$ Artaza 1922, pp. 158-159; 1959, pp. 239-240; Fernández 1998, pp. 681-682. Ante tales capillas y la portada norte, cuyo aspecto indica una apertura tardía con respecto a la fábrica original, nos preguntamos si podría haber existido una portada septentrional monumentalizada, a la manera de la norte de San Martín de Noia, pues sería factible que se hubiese concebido una portada con acceso inmediato a la villa.

${ }^{40}$ Es de gran interés el "descubrimiento" de dichas labras heráldicas alusivas al patronazgo del coro alto por don Rodrigo de Luna, puesto que la historiografía nunca las había reseñado. Tradicionalmente se ha atribuido a don Diego de Muros, coincidiendo con la elevación de la iglesia a colegiata en 1500, Caamaño 1962, pp. 120-121.
} 
observa la continuidad del patronazgo arzobispal en Muros, por parte de un prelado cuya propia heráldica evoca la de su antecesor don Lope de Mendoza.

\section{SAN MARTÍN DE NoIA: UNA "CATEDRAL" JACOBEA EN LA COSTA}

El 9 de abril de 1168 Fernando II otorga a Noia la Carta Puebla ${ }^{41}$ que la convierte en villa histórica ${ }^{42}$. El puerto se hallaba en la parroquia de Santa Cristina de Barro y la villa se sitúa en un lugar que, según la tradición, se denominaba San Martín de Sobreiral, por los árboles que allí había ${ }^{43}$. El burgo se construye por iniciativa del rey y del arzobispo, en un empeño en organizar la ría de Muros mediante la creación de un centro administrativo y militar bien conectado con Santiago, al tiempo que destacan los intereses económicos y señoriales, pues Noia es un apéndice de la Compostela artesana y comercial, regida por el fuero de Santiago ${ }^{44}$. Bajo la jurisdicción de la Mitra compostelana, Noia se convierte en el puerto de Santiago, pues su entrada en la ría de Muros era segura, tranquila y más rápida que la entrada al puerto de Padrón, al que iban si los vientos impedian dirigirse al puerto del Tambre ${ }^{45}$.

Otro de los hitos en la historia de Noia es la etapa del arzobispado de Berenguel de Landoria (1318-1330), quien, ante las dificultades con los compostelanos, se instala en ella, donde incluso celebra un sínodo en $1319^{46}$. Este prelado se preocupa de afianzarla como villa amurallada y puerto fortificado, al tiempo que se edifican dos hospitales y la iglesia de Santa María A Nova ${ }^{47}$, que consagra en 1327 y donde se efigia en su tímpano occidental. Don Berenguel era consciente de que una gran amenaza para Noia eran los caballeros, por entonces los Mariño y Soga de Lobeira, con los que esta villa pacta. Por su parte, él consigue entrar en Santiago el 20 de septiembre de 1320, tras ordenar el asesinato de su peor enemigo, Alonso Suárez de Deza. En 1330 los Churruchao, parientes de los Deza, poseían una fortaleza en la plaza del Tapal ${ }^{48}$, que pasa a manos de los arzobispos bajo el episcopado de don Martín Fernández

${ }^{41}$ Íntegro en latín en López 1901, vol. IV, apéndice XXXVIII, pp. $94-96$ y resumido en castellano en López 1895, vol. I, pp.159-161.

${ }^{42}$ Para las etapas anteriores: Nogueira 2017, pp. 13-19; Agrafoxo 2019, pp. 17-46.

${ }^{43}$ Agrafoxo 2019, p. 46.

${ }^{44}$ García 1987, vol. II, pp. 169-170.

${ }^{45}$ Miraz 2013, pp. 147-148. Así ocurre con los cruzados que en 1147 arriban a Noia, procedentes de Dartmouth, para visitar el sepulcro del apóstol, Alonso 1999.

${ }^{46}$ Ferreira 1988, pp. 89-90.

${ }^{47}$ García 1987, vol. II, p. 171.

${ }^{48}$ Nogueira 2005, p. 24. 
de $\operatorname{Gres}^{49}$ (1339-1342), emparentado con una rama de los Deza, afín a la Mitra. En ella, situada frente a la fachada principal de San Martín, pasarán numerosos momentos de reposo, utilizándola casi como residencia de costa.

Este enriquecimiento, sobre todo a través del puerto, especializado en la comercialización del pescado y sus derivados ${ }^{50}$, aumentó el interés de los caballeros - los Mariño de Lobeira y Pedro Enríquez de Castro-, por hacerse con el señorío de la villa; pero también de los hombres de Iglesia y los monasterios, que a lo largo de la segunda mitad del siglo XIV buscaban recibir parte de los bienes que procedían de Noia ${ }^{51}$.

En esta coyuntura se inicia el siglo XV y con él el arzobispado de don Lope de Mendoza. En Noia abundaba una población marinera bien acomoda$\mathrm{da}^{52}$, por lo que sigue siendo apetecible para la nobleza y, por supuesto, para el arzobispo. De hecho, en la documentación compilada por encargo de este prelado en 1435, editada bajo el título de Tumbo Vermello, se recogen la hazienda, renta y bienes, preeminencias y derechos ecclesiásticos y temporales que la Dignidad Arçobispal de Santiago tuvo ${ }^{53}$. En el estudio del editor se indica que el códice está formado de tres partes: la primera de autor desconocido escrita a finales del siglo XIV o inicios del XV, que recoge hechos acontecidos en el pontificado de Pedro V en 1345 y que alcanza hasta el folio 60r. Esta es la que nos importa, pues desde el folio $38 \mathrm{r}$ al 40v se señalan los derechos sobre Noia, que muestran la existencia, ya por entonces, de una rica iglesia parroquial de San Martín de la que al mayordomo se había de dar la mitad de sus frutos, ofrendas, mandas de los fallecidos y diezmos de los diferentes pescadores $^{54}$. Ello manifiesta la realidad que se impone a leyendas frecuentemente repetidas de que esta iglesia se erigió sobre otra dedicada a Santa María, lo que explicaría que la fundada por don Berenguel se denominase $A N o v a^{55}$. Se desconoce la data del edificio anterior, pues existen opiniones que van desde el siglo XII ${ }^{56}$ al XIII ${ }^{57}$, y que Caamaño documenta a través del testamento del canónigo compostelano Alonso Pérez, fechado en $1283^{58}$, lo que indica su

\footnotetext{
${ }^{49}$ Martínez 1888, p. 630.

${ }^{50}$ Sobre el comercio Ferreira 1988, p. 84, señala que era un puerto -junto con Pontevedra y Padrón- con mayor vitalidad y potencial que los de realengo. A partir de 1380 los que concentran la mayor actividad mercantil son A Coruña, Pontevedra, Noia y Muros, Ibidem, pp. 94-95.

${ }^{51}$ García 1987, vol. II, pp. 172-173.

${ }^{52}$ Ibidem, p. 172.

${ }^{53}$ Rodríguez 1994, pp. 51-61.

${ }^{54}$ Ibidem, pp. 54-56.

${ }^{55}$ Martínez 1888, p. 637.

${ }^{56}$ Nogueira 2005, p. 26.

${ }^{57}$ López 1904, vol. VII, p. 67.

58 “...predicte vinee et domus ad Ecclesiam sci Martini de Noia, deuoluantur". Caamaño 1960 , p. 68 , nota 184.
} 
existencia en el siglo XIII, y una gran riqueza en el siglo XIV, según se observa en el Tumbo Vermello.

La actividad de don Lope en esta villa parece la de un nuevo Berenguel: va a dejar su huella en la iglesia parroquial y en la fortaleza del Tapal, donde se halla su emblema heráldico, creando un entorno fortificado, como muestra la almenada cabecera de la iglesia de San Martín. Por lo que respecta a esta iglesia, no ha sido objeto de un estudio monográfico amplio, siendo los más relevantes los llevados a cabo por Caamaño ${ }^{59}$ y por Fernández Rodrígue $z^{60}$, ambos vinculados a sus respectivas tesis doctorales. La segunda autora lleva a cabo una recopilación de las referencias a esta iglesia desde el siglo XVII, por lo que remitimos a sus estudios ${ }^{61}$. Carecemos de documentos que indiquen el inicio del templo y sus autores, si bien existen dos elementos que apuntan claramente a la promoción por parte de don Lope de Mendoza: la heráldica, y un epígrafe en el dintel de la fachada principal en el que se grabó una cronología que se corresponde con la de su episcopado (fig. 5): ERA: DA NA(scen)ÇA: D(e): MCCCCXXXIIII ${ }^{62}$.

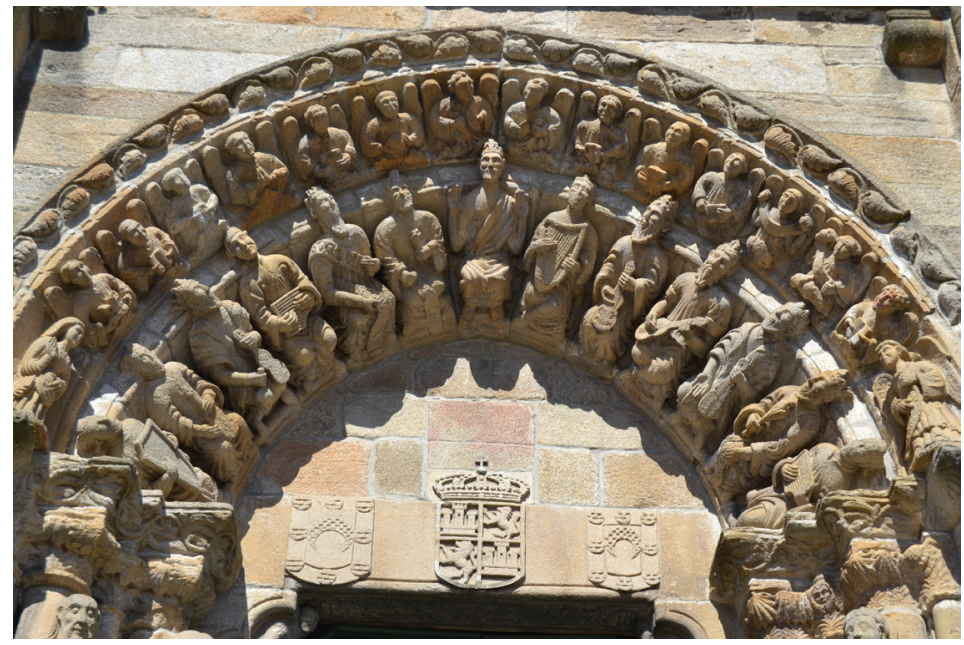

Fig. 5. San Martín de Noia. Escudos con las armas del arzobispo don Lope de Mendoza flanqueando el escudo con las armas del reino en el dintel de la portada occidental. Foto de los autores.

\footnotetext{
${ }^{59}$ Caamaño 1960, pp. 58-68; 1962, pp. 209-219; 1999, pp. 37-39; 2001, pp. 25-29.

${ }^{60}$ Fernández 1998, pp. 761-877; 1999, pp. 41-50; 2000a, pp. 81-88; 2000b, pp. 227-247; 2002, pp. 51-59.

${ }^{61}$ Fernández 1998, pp. 761-765; 2000b, p. 227.

${ }^{62}$ López 1904, vol. VII, p. 67.
} 
Habitualmente este año -1434- es considerado como el de la consagración de la iglesia, sin que se pueda corroborar con ningún otro testimonio. Es más, resulta una data "excesivamente jacobea", si tenemos en cuenta que, como ha estudiado López Alsina, se puede señalar que bajo el arzobispado de don Lope se habría introducido el año jubilar compostelano, bien tras la finalización del Cisma en el pontificado de Martín V (1417-1431), con un primer año jubilar en 1428, bien bajo Eugenio IV en 1434, momento a partir del cual ya se puede seguir la celebración regular de los Años Santos Compostelanos según los intervalos previstos -cuando la fiesta del Apóstol coincide en domingo ${ }^{63}$. Este arzobispo era un ferviente promotor de la gran perdonanza, no en vano funda una capilla dedicada a la Virgen del Perdón en la catedral, que será su lugar de enterramiento ${ }^{64}$. Es muy importante el apoyo que presta el rey Juan II, quien con fecha 1 de enero de 1434

expide un salvoconducto, en favor de los cristianos de Italia, Galia, Germania, Hungría, Dinamarca, Suecia, Noruega y otros lugares, para que hasta el 31 de diciembre transiten libremente por su reino en peregrinación al sepulcro de Santiago, "tam per terras quam per aquas" ${ }^{\prime 65}$.

Una consecuencia cuantificable fue el incremento de licencias concedidas a peregrinos para viajar a Galicia. En los años del arzobispado de don Lope habría dos años jacobeos (1428 y 1434) y el siguiente (1445) ya se corresponde con el de su fallecimiento en febrero y el inicio del gobierno de su sucesor don Álvaro Núñez de Isorna. La fecha de 1428 es importante para Noia pues don Lope le concede fueros; en realidad son los mismos que se otorgan a Pontevedra, salvo que en Noia el mayordomo tenía mayores atribuciones, pues el arzobispo no solo era señor del territorio, sino patrono de la iglesia y propietario de gran parte de la comarca ${ }^{66}$.

Estos datos son de especial relevancia ante la carencia de documentos que justifiquen el proceso constructivo de la iglesia de San Martín de Noia, así como de su iconografía. Por lo que se refiere al primer aspecto, Caamaño considera que se trató de una construcción bastante homogénea, obra en conjunto del primer tercio del siglo $\mathrm{XV}^{67}$. Él propuso que se habría iniciado por los pies por la existencia de una iglesia anterior, y considera que cuando se colocó el dintel de la puerta principal debía de estar hecha la fachada, si no en

\footnotetext{
${ }^{63}$ López 1999, p. 235.

${ }^{64}$ Ibidem, p. 234.

${ }^{65}$ Ibidem, p. 238.

${ }^{66}$ López 1895, vol. II, pp. 116-122.

${ }^{67}$ Caamaño 1960, p. 68.
} 
su totalidad, sí hasta la cornisa que separa la puerta del rosetón, así como los muros de la nave, pues en el cuarto tramo -él cuenta desde los pies- se halla su escudo. En su opinión, la capilla mayor sería lo último en construirse, con poca diferencia del resto. Ya en un período posterior sitúa la tribuna -que data a fines del XV o incluso principios del XVI-, al igual que el segundo cuerpo de las torres -de inicios del XVI- y la capilla de Valderrama, de comienzos del XVII ${ }^{68}$.

Por su parte Fernández Rodríguez considera que las obras se debieron de realizar en sentido contrario, emprendiendo el prelado compostelano la capilla mayor y el cierre de los dos primeros tramos de la nave, que presentan una continuidad estructural y decorativa, quedando su labor inconclusa en los dos últimos ${ }^{69}$. No obstante, durante el arzobispado de don Lope se completaría el perímetro de la iglesia, incluida buena parte de la fachada, para proceder, a continuación, a la organización del espacio interno, planificado como una iglesia de tres naves con cabecera hemipoligonal, como se observa en el arranque de sendos arcos formeros, proyecto que fue abandonado, bien por problemas económicos o bien por falta de espacio para la división tripartita ${ }^{70}$.

En efecto, una simple observación del interior permite ver que un primer proyecto habría previsto una iglesia de tres naves (fig. 6), que se paraliza tras haber iniciado el arranque de los arcos formeros. Asimismo, se puede comprobar que existe una uniformidad constructiva en el lado norte hasta el tercer tramo - contando desde la cabecera-, donde se abre una puerta en cuyo tímpano se representa la Virgen con el Niño, flanqueada por san José y la figura de un obispo (fig. 7), sobre la que volveremos. Sin embargo, en el lado sur se observa una notable ruptura constructiva en la parte superior, que permite suponer que la promoción de don Lope habría avanzado más por el lado norte que por el sur, si bien en la parte superior se observan con claridad dos modelos en los enormes arcos perpiaños que sujetan la armadura de madera: el arco triunfal y los de los dos primeros tramos poseen una decoración de gruesos baquetones con rosáceas, que suponen el resurgimiento de motivos mateanos, mientras que los dos últimos son lisos (fig. 8) ${ }^{71}$.

${ }^{68}$ Ibidem.

${ }^{69}$ Fernández 2000b, p. 246.

${ }^{70}$ Ibidem, pp. 246-247.

${ }^{71}$ El estudio estilístico de los capiteles, así como los motivos decorativos, ha sido realizado con gran acierto por Fernández 1998, pp. 778-814. 


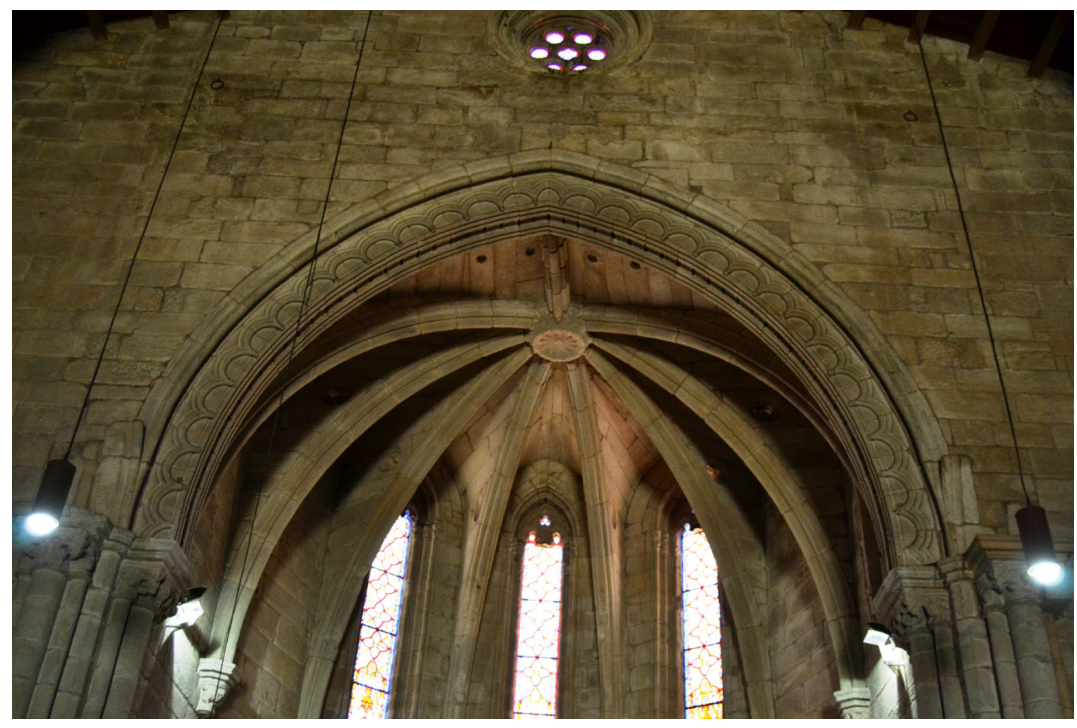

Fig. 6. San Martín de Noia. Interior de la nave hacia el ábside. Foto de los autores.

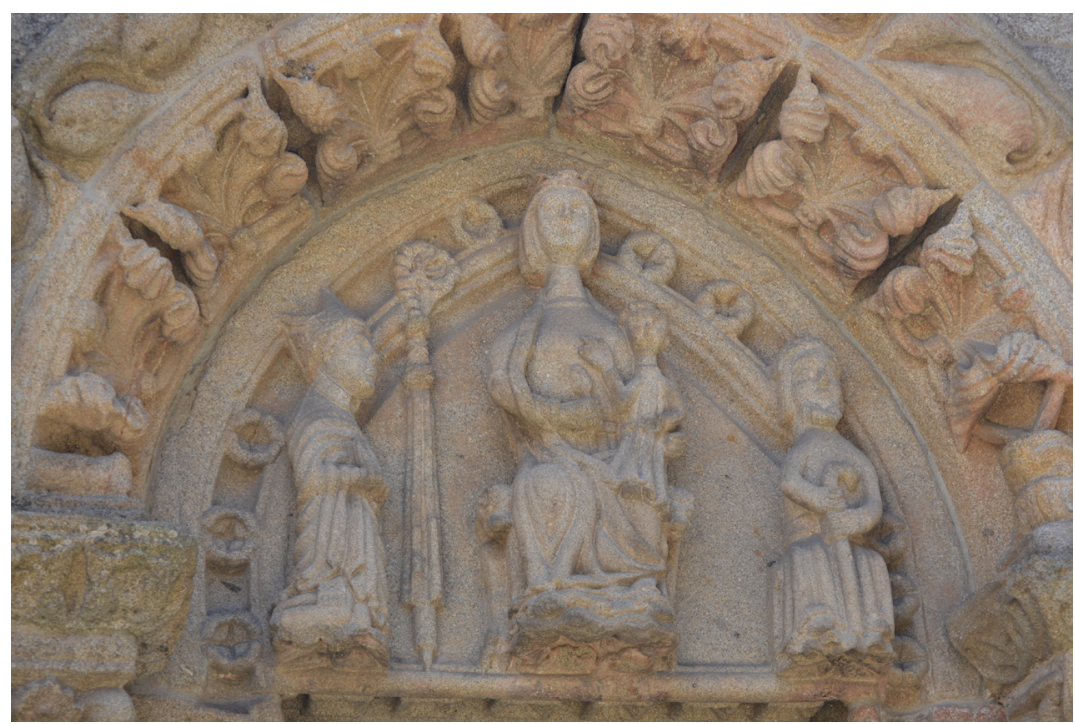

Fig. 7. San Martín de Noia. Tímpano de la portada norte. Foto de los autores. 


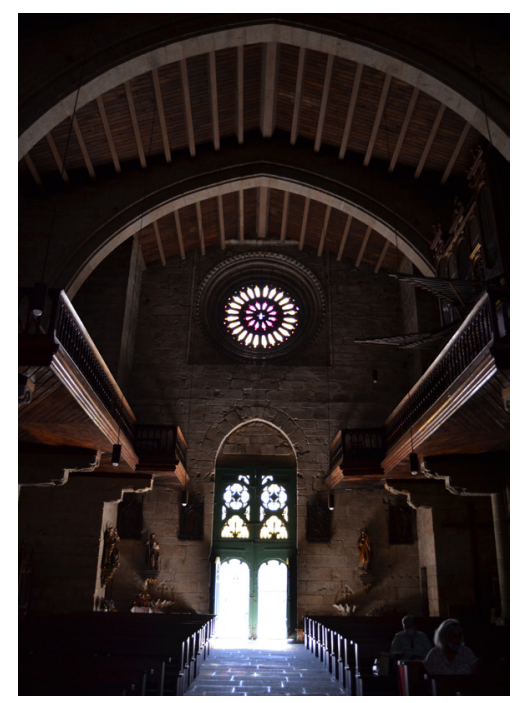

Fig. 8. San Martín de Noia. Interior de la nave. Vista hacia la portada occidental y tribunas laterales. Foto de los autores.

Sobre la continuidad de la obra de este templo tras la promoción de don Lope, Caamaño no aporta ninguna hipótesis, mientras que Fernández Rodríguez lo hace apoyándose en la heráldica de la fachada. En ella se observa en el dintel el escudo de Castilla y León flanqueado por sendos emblemas heráldicos de don Lope de Mendoza. Esta combinación no es nueva, pues se encuentra en el cimborrio de la catedral compostelana, financiado asimismo por este prelado, e iniciado en $1422^{72}$. Lo que resulta llamativo es la presencia de la corona sobre el escudo del reino, que es fruto de alguna restauración probablemente del siglo $\mathrm{XX}^{73}$, puesto que no se hallaba en la imagen que proporciona Martínez Murguía, anterior a $1888^{74}$, ni en la xilografía de A. Hébert publicada en La Ilustración Española y Americana ${ }^{75}$ en 1884 (fig. 9). El otro escudo que se aprecia con claridad, a pesar del desgaste, se dispone en la torre norte y se corresponde con el del arzobispo Álvaro Núñez de Isorna (1445-1449), sucesor

72 Manso 1996, pp. 358-360. Caamaño 1960, p. 43, todavía interpretaba la ERA 1422 como era hispánica, por lo tanto 1384 , por lo que consideraba a don Lope como continuador de la obra. El cimborrio ha sido objeto de estudio en Vázquez 2009.

${ }^{73}$ Sabemos que en 1895 se restauró el rosetón principal de la iglesia, como se observa claramente, y se dispuso la reja ante la puerta principal: Nogueira 2017, p. 29.

${ }^{74}$ Martínez 1888, p. 639.

${ }^{75}$ Faginas 1884, pp. 205-206. 
de don Lope; presenta un cuartelado con lises y correas ${ }^{76}$. En esta misma torre, bajo la campana, Fernández Rodríguez consideró que se encontraba el emblema de don Martín Rodríguez de Junqueras - que ella sitúa en la torre derecha- y que describe como en un campo de plata un manojo de juncos, complementándose con una inscripción en letra gótica ${ }^{77}$. Sin embargo, lo que observamos es un cáliz, dispuesto a modo de señal heráldica, con una inscripción en letra gótica, que no logramos descifrar, que probablemente deba relacionarse con la cuestión eucarística $^{78}$. Por consiguiente, si tomamos la heráldica como único referente documental, tendríamos que considerar que la obra no habría sido concluida por don Lope de Mendoza, sino que la proseguiría su sucesor en la sede compostelana, don Álvaro Núñez de Isorna, quien se ocuparía de las partes altas del templo, y tal vez de las ménsulas que sostienen las dos tribunas ${ }^{79}$. Recordemos que, en el templo de Santa María de Muros, el coro alto cuenta con el refrendo de la presencia del escudo de don Rodrigo de Luna, sucesor de don Álvaro.

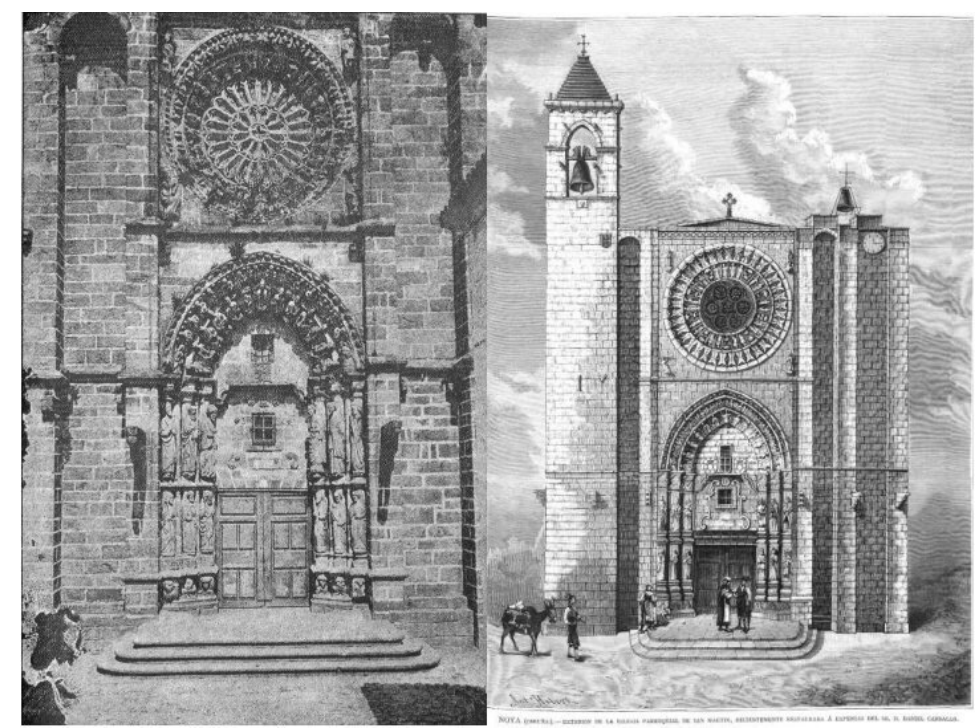

Fig. 9. San Martín de Noia. Imagen de Murguía (1988) y xilografía de A. Hébert (La Ilustración Española y Americana 1884).

\footnotetext{
${ }^{76} \mathrm{Su}$ emblema heráldico se puede observar en su sepulcro, estudiado en Cendón 1995, así como en la peana de la imagen de Santiago peregrino, realizada en plata dorada, con esmaltes, Fandiño 2019, pp. 52-55.

${ }^{77}$ Fernández 1998, p. 813; 2000b, p. 232.

${ }^{78}$ Agradecemos las observaciones que nos ha proporcionado don Eduardo Pardo de Guevara y Valdés.

${ }^{79}$ Sobre su iconografía véase Fernández 1998, p. 813.
} 
Por lo que respecta a la iconografía de las puertas norte y oeste de San Martín de Noia -la sur se encuentra tapiada-, en la primera, a la que ya hemos hecho referencia, se halla una imagen episcopal arrodillada. Para algunos autores se podría tratar del patrono del templo, san Martín ${ }^{80}$, del cual no se conserva ninguna imagen medieval en el conjunto. Sin embargo, Caamaño propuso que se podría considerar don Lope de Mendoza, arrodillado, con capa pluvial, mitra y báculo ${ }^{81}$. Es una identificación que compartimos ${ }^{82}$, teniendo en cuenta el paralelismo que ofrece con la representación de don Berenguel en el tímpano de Santa María a Nova, aquel inserto en la escena de la Epifanía: ambos arrodillados, con las manos en oración; sin embargo, si el primero posee la iconografía característica del donante, en este caso adquiere un protagonismo incluso superior al de san José, pues ocupa el lado preferente. Por otro lado, hay dos elementos que llaman la atención: la imposibilidad de apreciar el palio y el tipo de báculo con panisellus, pero remate en voluta, en lugar de "tau", que utilizan los arzobispos compostelanos a partir del episcopado de don Pedro Suárez de Deza (1173-1206) ${ }^{83}$ y que porta el propio don Lope de Mendoza en la peana en la que es representado arrodillado a los pies de la Virgen del Perdón. Esta comparación permite, a su vez, incidir en las divergencias tanto técnicas como iconográficas existentes entre producciones artísticas coetáneas que, al ser realizadas en granito, no permiten una aproximación al detalle como ocurre con el alabastro, confiriéndoles un aspecto arcaizante, a pesar de su avanzada cronología. Por otro lado, en la escultura gallega de esta época no existe una aproximación al retrato ${ }^{84}$.

En la portada occidental, la iconografía hace hincapié en el carácter jacobeo, con una evocación del Pórtico de la Gloria, pero ya dentro de la espiritualidad propia del siglo XV: María tiene una presencia inexistente en el pórtico compostelano, y se recogen los arma Christi en el rosetón, dentro del proceso de humanización de la figura de Cristo sufriente, cuya sangre derramada también se pone de manifiesto en la representación del cáliz al que antes nos referimos, y que está en consonancia con la devotio moderna y la expansión de textos como las Meditationes Vitae Christi, así como con la labor de las órdenes mendicantes que tanto auge tuvieron en todo el reino. Carecemos, no obstante, de referencias documentales que permitan conocer la recepción de estos motivos por parte del público, si bien es importante tener en cuenta la existencia de un mercado en este entorno, como reflejan los volados

\footnotetext{
${ }^{80}$ Martínez 1888, p. 640; Nogueira 2017, p. 27.

${ }^{81}$ Caamaño 1962, p. 218. Opinión que reitera Fernández 2000a, pp. 86-87.

${ }^{82}$ Cendón, Barral, Fraga 2000, p. 51.

${ }^{83}$ Moralejo 1993.

${ }^{84}$ Cendón, Barral 1999, p. 394.
} 
mensulones que emergen de los muros norte y occidental, precisamente aquellos con mayor desarrollo iconográfico ${ }^{85}$.

Lo primero que llama la atención de la portada es la presencia del apostolado, que se dispone en tres columnas acodilladas a ambos lados de la puerta, en dos niveles superpuestos (fig. 10). En ella se repite, en la primera columna del lado izquierdo, la imagen de Santiago el Mayor, con dos iconografías diferentes: la superior porta una cartela en la mano derecha, y báculo en "tau" con panisellus y una venera en el astil, en la izquierda; la inferior porta bordón de doble pomo en la mano izquierda y libro en la derecha; en ambas destaca el sombrero característico del peregrino, en la superior con el ala redondeada y una gran venera sobre ella, y en la inferior el ala vuelta, plana y una venera pequeña. Finalmente, para ahondar todavía más en el carácter jacobeo, los capiteles poseen decoración de veneras, símbolo de la peregrinación a Santiago ${ }^{86}$. No parece casual, cuando se pretende dejar clara la huella de la Mitra compostelana en una iglesia que se situaba frente a una residencia arzobispal, y que convierte una iglesia parroquial casi en una catedral.

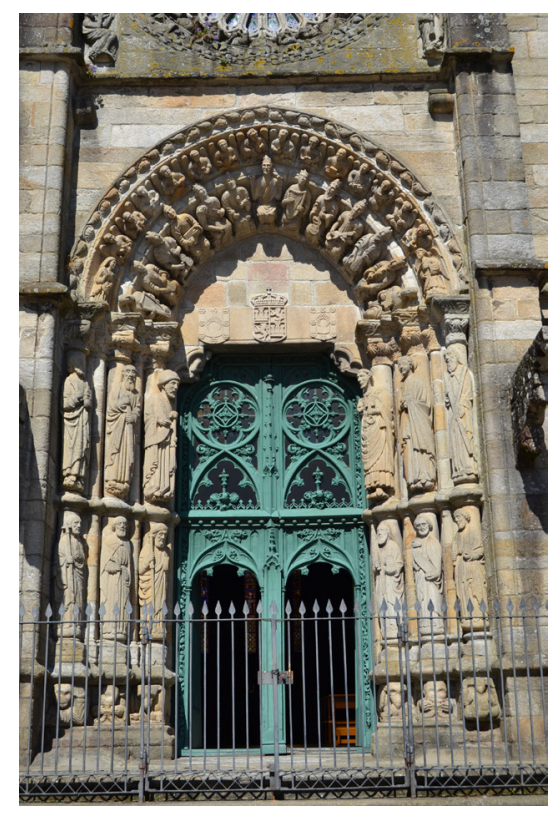

Fig. 10. San Martín de Noia. Portada occidental. Foto de los autores.

\footnotetext{
${ }^{85}$ También desconocemos los posibles ritos y ceremonias litúrgicas o incluso civiles que se podrían haber desarrollado en este entorno privilegiado.

${ }^{86}$ Sobre el significado de la venera, Vázquez de Parga 1948, pp. 129-130; Castelli 1995.
} 
Por lo que respecta a las siguientes representaciones de los apóstoles han sido estudiadas por Caamaño ${ }^{87}$ y Fernández Rodríguez ${ }^{88}$. Algunos son de fácil identificación, mientras otros ofrecen ciertas dudas: en la parte superior, del lado izquierdo, se encuentra san Pablo, con su característica alopecia y una espada cuyos gavilanes curvos indican que la imagen se adapta a la evolución de esta arma, correspondiente al siglo XV, y no se copia el modelo del Pórtico de la Gloria. El último apóstol del lado izquierdo, según Caamaño, portaría una porra o maza en la izquierda y un libro en la derecha, mientras Fernández Rodríguez considera que se trata de una maza o garrote. El primero supone que se trataría de Simón o Santiago el Menor, opción por la que se decanta la segunda. Sin embargo, consideramos que porta una daga, comparable con la que caracteriza a san Bartolomé en dos obras que se han vinculado con el taller de Noia y con el desaparecido sepulcro de don Lope de Mendoza, respectivamente: la portada de la actual catedral -desde 1977- de Viana do Castelo, datada $c a .1433-1485^{89}$ (fig. 11) y el sepulcro de don Diego de Anaya, realizado $c a .1425-1435^{90}$. Por comparación con la Virgen del Perdón, y debido a que las descripciones del conjunto funerario indicaban que en él se había representado un apostolado ${ }^{91}$, cabe pensar que quizá el "Maestro de Anaya", o alguien de su taller, hubiesen realizado la tumba del arzobispo compostelano; de hecho no es el único elemento que evoca en esta fachada la iconografía del sepulcro de Anaya. Asimismo, bajo sus pies se halla una figura demoníaca, elemento que suele figurar en las representaciones de este santo ${ }^{92}$. Un elemento más de apoyo a la identificación de esta imagen con san Bartolomé es que este apóstol es el patrono de la villa, si bien existen discrepancias sobre el inicio de ese patronazgo ${ }^{93}$.

${ }^{87}$ Caamaño 1960, pp. 63-64; 1962, p. 216.

${ }^{88}$ Fernández 1998, pp. 853-865; 1999, pp. 41-50.

${ }^{89}$ Gonçalves 1961; Vilarinho 2014, pp.129-130; Ramos 2018, pp. 78-79.

${ }^{90}$ Cendón 1996, p. 883.

${ }^{91}$ Taín 2019, p. 70: "y en medio de ella está un excelente y suntuoso sepulcro, de fino alabastro, muy blanco, del que hay en tierra de Lemos del Yncio, labrado y esculpido de muchas figuras, grandes y pequeñas. Sostienenle 12 leones del mismo mármol y en cada uno un escudito de sus armas (pequeño). Tiene bulto y retrato de su persona, tendido a lo largo, como se usaba en aquellos tiempos hasta el de los Reyes Católicos, vestido de pontifical, con su báculo. Y la cabecera un Cristo dibujado. Y a los lados y pies los doce apóstoles y evangelistas".

${ }_{92}$ Ferrando 1950, p. 57.

${ }_{93}$ Carré 1928 considera que el primer patrón era san Bartolomé, p. 526. Fabeiro, Fernández 2001, pp. 15-16 opinan que san Martín y san Bartolomé eran copatronos de la villa. Caamaño 2005 se pregunta por qué en la actualidad san Bartolomé ha desplazado a san Martín como patrono, y plantea como hipótesis el hecho de que el primero hubiese sido el patrono de alguno de los gremios más relevantes de la villa, a cuyos habitantes se les conocía como "zapateiros". Sin embargo, García 1991, p. 30, indica que el patrono de los zapateros en 1567 era san Martín y san Bartolomé no figura en ninguno de los gremios que él señala. 


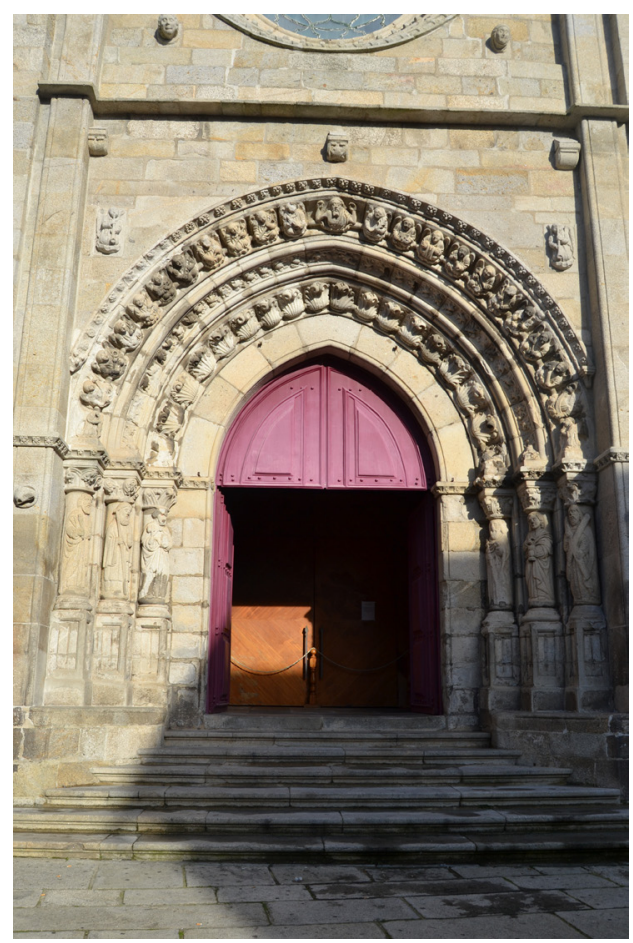

Fig. 11. Catedral actual de Viana do Castelo (Portugal). Portada occidental. Foto de los autores.

En la parte inferior, en el lado izquierdo, la figura central es santo Tomás, que porta un cinturón; este atributo incide en su incredulidad, pues le habría sido entregado por parte de la Virgen, durante su elevación al cielo, para que creyera en su Asunción ${ }^{94}$. La representación de este apóstol con cinturón no es la más frecuente -suele portar la lanza de su martirio o una escuadra de arquitecto-, pero es la que se encuentra en el sepulcro de Anaya. Cabe pensar en alguna vinculación entre el sepulcro del arzobispo y Noia; de ser así, estaríamos en una cronología un poco más tardía, pues la capilla del Perdón, donde se ubicó el sepulcro, habría sido comenzada en 1442 y concluida en $1451^{95}$. La última imagen de ese costado es la de san Felipe, con una cruz griega como remate de un largo astil.

Por lo que respecta al lado derecho, comenzando de nuevo por la parte superior, se encuentra san Pedro. En este caso, al igual que en el Pórtico

\footnotetext{
${ }^{94}$ Réau 1998, vol. II-5, p. 269.

${ }^{95}$ Cendón, Barral, Fraga 2000, p. 57; Yzquierdo 2006-2007, pp.140, 154.
} 
de la Gloria, viste indumentaria litúrgica, sostiene las llaves con la izquierda, mientras bendice, al modo gótico, con la derecha. Le sigue la imagen del apóstol san Juan, joven, imberbe y esbozando una leve sonrisa, que porta un libro con la izquierda, mientras lo señala con la diestra. Por último, se encuentra Andrés, con la cruz en aspa, ataviado con túnica y un manto que cierra con un broche en la parte delantera, al igual que ocurre con Tomás.

En la parte inferior, la figura más cercana a la puerta porta una sierra, atributo que normalmente corresponde a Simón. Sin embargo, en la peana existen restos de una inscripción que lo identifica con Judas Tadeo ${ }^{96}$; quizá esta discrepancia entre el atributo y el epígrafe pueda deberse al hecho de que ambos sufrieron el martirio conjuntamente. A continuación se halla una figura de barba corta que sostiene una larga filacteria, cuya inscripción en la peana es actualmente ilegible; Caamaño planteó la posibilidad de que se tratase de Mateo ${ }^{97}$, opinión que reitera Fernández Rodríguez ${ }^{98}$. Si volvemos a tomar como referente el sepulcro de Anaya, tres de los apóstoles portan una larga cartela, entre los cuales hemos supuesto que se trataría de Felipe, Simón, Judas Tadeo o Mateo ${ }^{99}$. Teniendo en cuenta que en este caso Felipe es perfectamente identificable y Judas Tadeo posee la inscripción, podría tratarse de Mateo. El último apóstol porta un libro y un hacha, atributo que suele vincularse con Matías, que, por lo general, es el que se suprime en favor de san Pablo. Por tanto, se prescindiría de Simón y Santiago el Menor.

Sobre el apostolado se erige una doble arquivolta, eco, una vez más, del Pórtico de Gloria, pero con diferencias significativas. La arquivolta externa presenta catorce ángeles: los centrales turiferarios son los únicos que parecen funcionar como pareja, mientras los restantes llevan libro o cartela, aludiendo a la Nueva y Antigua Ley; alguno dispone su mano en actitud orante y otro lleva una redoma, cada uno en disposición frontal dentro de su dovela. Pero lo más novedoso se halla en los salmeres: el izquierdo está ocupado por una imagen de la Virgen de la $\mathrm{O}$, con la mano derecha en gesto de aceptación -Fiat- y la izquierda sobre el vientre. Esta iconografía, llegada a Galicia desde los talleres conimbricenses de Mestro Pero ${ }^{100}$, tuvo una gran expansión desde el segundo tercio del siglo XIV. En este caso, además de la presencia del arcángel Gabriel en el salmer del lado derecho, se completa con el ángel que se dispone en la dovela siguiente a la Virgen, el cual porta una corona: la Coronación de la Virgen es uno de los temas característicos del gótico, y está ausente en la catedral compostelana.

\footnotetext{
${ }^{96}$ Caamaño 1960, p. 64; 1962, p. 216.

${ }^{97}$ Ibidem.

${ }_{98}^{98}$ Fernández 1998, p. 861; 1999, p. 47.

${ }^{99}$ Cendón 2003, pp. 46-47.

${ }^{100}$ Cendón 2017, pp. 454-462.
} 
En la arquivolta interior, de mucha más anchura, se encuentra en el vértice Cristo mostrando las llagas $\mathrm{y}$, a ambos lados, doce personajes que difieren de los ancianos del apocalipsis, no solo por su número, su frontalidad o la representación de un menor número de instrumentos musicales ${ }^{101}$, sino también porque en tres de los casos se incluyen personajes de la Antigua Ley ${ }^{102}$, que marcarían el contraste con la escena de la Anunciación.

La fachada culmina con un espléndido rosetón (fig. 12), del cual solo se ha identificado la figura central hacia la derecha: una imagen de la Virgen rodeada por ángeles que alternan con grandes hojas carnosas ${ }^{103}$. Fernández Rodríguez señala los cuatro ángeles trompeteros que rodean el rosetón, que anunciarían el comienzo del Juicio Final. Tres de ellos están de pie y uno sentado; este último semejante al de la esquina de la nave del evangelio en el Pórtico compostelano, mientras los restantes evocan los que ocupan las trompas del cimborrio, realizados bajo la promoción artística de don Lope de Mendoza; con ellos comparten detalles como la botonadura en las mangas y los carrillos hinchados en el momento de hacer sonar las trompetas.

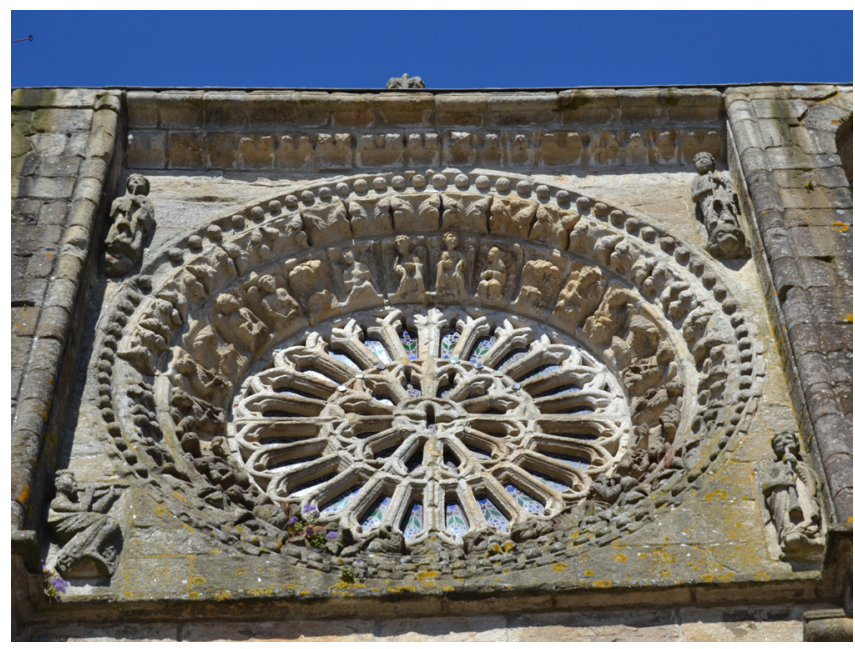

Fig. 12. San Martín de Noia. Rosetón de la fachada occidental. Foto de los autores.

Lo que nadie ha destacado hasta ahora es el hecho de que los ángeles que pueblan el rosetón -excepto el que ocupa la parte central junto a la imagen de la Virgen, inserta sobre un motivo que evoca los rayos y que por su ubicación

\footnotetext{
${ }^{101}$ Fernández 1998, pp. 850-851.

${ }^{102}$ Caamaño 1991, p. 444.

${ }^{103}$ Caamaño 1960, p. 63; 1962, p. 215.
} 
podría sugerir la presencia de la Virgen en el cielo-, un total de 18, portan los instrumentos de la pasión. Este elemento, ya presente en el Pórtico de la Gloria, adquiere aquí un significado en consonancia con la espiritualidad de esta época. Siguiendo el movimiento de las agujas del reloj se puede apreciar la imagen de Judas ahorcado con la lengua fuera, la daga de Pedro, la cruz, el flagelo, la corona, el martillo, la esponja, la lanza, la bolsa de denarios, los dados, las tenazas, la escalera, los clavos, la columna y la Santa Faz.

Para completar el conjunto, hemos de acudir, de nuevo, a un ejemplo con el que las similitudes son notables: la actual catedral de Viana do Castelo, por entonces parroquial, iniciada hacia 1400 con la llegada al trono de la nueva dinastía de los Avis. En ese momento se estaba viviendo una situación peculiar: Viana, pese a estar bajo la corona lusa, pertenecía a la diócesis de Tui que llegaba hasta el río Limia. En el Cisma de Occidente (1378-1417), en un primer momento Castilla y Portugal apoyaron a Clemente VII, pero tras la proclamación de João I, los portugueses secundaron al papa romano Urbano $\mathrm{VI}^{104}$. En 1381 parte del clero tudense se trasladó a Valença do Minho donde elevaron la iglesia de San Esteban al rango de colegiata. Cuando terminó el Cisma, el rey portugués obtuvo una bula papal de Eugenio IV en 1444 para que la parte portuguesa de Tui se integrase en la diócesis de Ceuta, hasta que en 1512 estas tierras se incorporaron al arzobispado de Braga ${ }^{105}$. Por ello, la iglesia de Viana se iniciaría en ese momento de ruptura, en el que la parte portuguesa del obispado tudense se había independizado, y se remata cuando pertenecía al obispado de Ceuta.

Desde la historiografía española no conocemos ningún autor que haya puesto en relación este ejemplo con la iglesia de San Martín de Noia ${ }^{106}$. Si bien hay numerosas diferencias, hay otros puntos en común: lo que en Noia ocupa el rosetón, aquí se dispone en la tercera arquivolta, donde los ángeles portan los instrumentos de la pasión, excepto los dos primeros que sustentan cartelas, de las cuales en la derecha se puede leer: SURGITE MORTUI VENIT A JUDICIUM. Si seguimos la identificación de los instrumentos de la pasión, de izquierda a derecha, vemos la cuerda, una palma, el flagelo, los clavos, la escalera, el martillo, la esponja, la cruz, y la daga de Pedro. En la clave, Cristo

${ }^{104}$ Almeida 1967, pp. 285-287.

${ }^{105}$ Iglesias 2008, pp. 103-112.

106 "Assemelha-se a outros pórticos de igrejas galegas, nomeadamente ao da igreja de S. Martin, em Noya, levando Flávio Gonçalves e Vergílio Correia a atribuírem-no ao mesmo autor, que, segundo pensam, teria chegado a Viana depois de 1434, depois da conclusão da igreja galega. A semelhança entre Noya e Viana é, essencialmente, compositiva, sendo as imagens desta última estáticas, atarracadas e bastante grossas e as arquivoltas, ainda que esquemáticas, têm também decoração mais românica do que gótica e os figurados, ao contrário do que se passa neste estilo, estadeiam-se numa posição transversal às arquivoltas”, Figueiredo, Noé 2004-2005. 
mostrando las llagas. A continuación, una palma, los dados, la Santa Faz, la bolsa de denarios, las tenazas, otro flagelo, la corona, la lanza y la columna. Como se puede apreciar, un total de 18 instrumentos de la pasión, número que coincidiría con el de Noia.

Fernández Rodríguez ha considerado que en el apostolado de Noia habrían participado tres maestros: al primero se deberían las figuras de Santiago el Mayor, Pedro y Juan; al segundo, Bartolomé, Pablo, el Santiago del piso inferior, Judas Tadeo, Mateo y Matías; y, por último, al tercero y menos cualificado, Andrés, Tomás y Felipe ${ }^{107}$. En Viana encontramos la representación de Bartolomé, Santiago el Mayor -semejante al del piso bajo- y Pedro (que nada tiene que ver con la imagen noiesa), en el lado izquierdo; y Pablo, Juan -totalmente distinto al de Noia-y Andrés, en el derecho. Por ello podemos deducir que el que Fernández Rodríguez identificó con el primer maestro, no se habría desplazado a Viana.

\section{CONCLUSIONES}

Don Lope de Mendoza tuvo un largo arzobispado en Compostela, a la vez que una estrecha relación con la monarquía, en especial bajo el reinado de Juan II. Como en el caso de don Berenguel de Landoria, y en aras a reivindicar su condición señorial sobre villas como las de Muros y Noia, don Lope recurre a la promoción artística como fórmula propagandística de exaltación del poder y prestigio de los arzobispos de Santiago, aunque también de su propia persona, como miembro de un linaje destacado que ha logrado ascender a la sede compostelana. Don Lope se inscribe, por tanto, en una tendencia que se observa en numerosos prelados, ejerciendo un patronazgo activo a la hora de impulsar la edificación de monumentales conjuntos eclesiales. Al fin y al cabo en sus pétreos muros podían incorporar heráldica, retrato artístico - piadoso-y/o inscripción identificativa, conformando esa simbólica panoplia visual como refrendo de su iniciativa, tan virtuosa como interesada. Amén de servir de apoyatura para un acceso de su alma a la Gloria, pues tales alusiones monumentales dejaban asegurada la pervivencia de su memoria y fama, más allá de los tiempos de su propia existencia.

Ya desde los inicios de su episcopado compostelano, y con la experiencia previa mindoniense, se observa su interés en la potenciación de las villas portuarias de la Tierra de Santiago, tan rentables para la Mitra como emergente alternativa de poder frente la levantisca nobleza tradicional. El

${ }^{107}$ Fernández 1998, pp. 871-877; 1999, p. 47. 
caso de Muros resulta significativo, pues se aprecia como uno de los linajes urbanos, los Affonso, cuyos miembros se suceden en el oficio notarial y participan del poder municipal, son promovidos por don Lope en el organigrama concejil. Por ello no es casual que Lorenzo Affonso sea nombrado por el propio arzobispo como procurador de la obra de la nueva iglesia parroquial de Santa María do Campo, con un vínculo que se traduce en la conformación de su panteón en la nueva capilla mayor, donde se conserva su sepulcro. Y de manera paralela, don Lope hace plenamente visible su condición señorial sobre la villa a partir de su compromiso promotor con dicha empresa constructiva, tanto de manera directa como a través de un concejo que camina de su mano.

El resultado supone la realización de una fábrica dentro de los parámetros del "gótico marinero", y cuyo proyecto primigenio -capilla mayor y amplia nave con cubierta soportada por grandes arcos perpiaños- habría de ser rematada aún en vida de don Lope. La heráldica y las inscripciones se convierten en el testimonio gráfico de la participación activa del arzobispo en la construcción y, por consiguiente, en la mejora y engrandecimiento de la villa, aspectos que redundan en el afianzamiento de su prestigio y fijación de una buena memoria. Si el modelo para tal empresa muradana pudo haber sido la iglesia de Santa María a Nova de Noia, iniciativa de don Berenguel de Landoria, el consecuente directo habrá de verse en la promoción arzobispal sobre la grandiosa iglesia noiesa de San Martín.

La relación de don Lope de Mendoza con la villa de Noia es muy estrecha, no solo por su papel como puerto de Santiago, sino por la importancia que para los arzobispos compostelanos tenía la fortaleza del Tapal. Esta se encontraba frente a una antigua iglesia parroquial que don Lope reedifica -con una plaza del mercado en ese entorno-, convirtiéndola en una "catedral" en la costa, cuya cabecera almena, estableciéndose un diálogo entre la iglesia y el palacio arzobispal, semejante al que se observaba en la catedral de Santiago, cuyo cimborrio, a modo de gran torre acastillada, es promovido por este arzobispo. Ello ratifica la vinculación existente entre esta villa y la capital de la archidiócesis, que no existe en el caso de Muros, demostrando la alta consideración de Noia, que busca referentes directos en la propia sede apostólica.

En la iglesia de San Martín de Noia su huella se hace patente en casi toda la construcción, como refleja la presencia de su heráldica en la fachada y en el exterior, en el lado norte, muy cerca de la puerta en la que es efigiado junto a la Virgen que bendice su promoción. En la fachada occidental, eco del Pórtico de la Gloria, la presencia jacobea es mucho más sutil, con la reiteración de la imagen de Santiago el Mayor, la decoración de los capiteles con veneras, y la data que se graba en el dintel, 1434, fecha del primer o segundo año jubilar compostelano, recién oficializado. 
Por otro lado, las representaciones marianas responden a una devoción especialmente querida para don Lope, quien dedica su capilla funeraria a la Virgen del Perdón. En Noia, al contrario de lo que ocurre en la obra románica de la catedral compostelana, se muestra una presencia muy destacada de la Virgen (no en vano nos encontramos en una fase avanzada del gótico): la Anunciación, la Coronación y su ubicación en los cielos se complementa con otros elementos propios de la espiritualidad de la época; es el caso de la presencia de los arma Christi, propios de los presupuestos de la devotio moderna, de ese Cristo redentor que tras su Pasión, Muerte y Resurrección libra a la humanidad del pecado, que en la fachada queda constreñido en la base de las jambas, sobre las que se disponen los apóstoles, transmisores de la Nueva Ley.

Los restos conservados indican que don Lope no habría rematado todo el conjunto, pues la presencia del emblema heráldico de su sucesor, don Álvaro de Isorna, lleva a suponer que él culminaría las partes superiores, mostrando, a pesar de su corto pontificado, que la villa de Noia ocupaba un lugar muy destacado en las preocupaciones de los arzobispos.

\section{BIBLIOGRAFÍA CITADA}

Agrafoxo Pérez, Xerardo (2019), Historia de Noia, A Coruña, Deputación da Coruña - Concello de Noia.

Almeida, Fortunato de (1967), História da Igreja em Portugal, Porto, Portucalense Editora.

Alonso Romero, Fernando (1999), La arribada de la flota británica al puerto de Noia en 1147, en Mostra Filatélica Internacional, Noia, Grupo Filatélico y Numismático, pp. 31-34.

Alonso Ruiz, Begoña; Martínez de Aguirre, Javier (2011), Arquitectura en la Corona de Castilla en torno a 1412, "Artigrama" 26, pp. 103-147.

Artaza y Malvárez, Ramón de (1922), Muros: Páginas de su historia, Vigo, El Heraldo de Vigo.

Artaza y Malvárez, Ramón de (1959), La villa de Muros y su distrito, Pontevedra, Ayuntamiento de Muros.

Bango Torviso, Isidro G. (1992), El espacio para enterramientos privilegiados en la arquitectura medieval española, "Anuario del Departamento de Historia y Teoría del Arte" 4, pp. 93-132.

Caamaño Martínez, Jesús María (1960), El arzobispo compostelano Don Lope de Mendoza (†1445) y sus empresas artísticas, "Boletín del Seminario de Estudios de Arte y Arqueología" 26, pp. 17-68.

Caamaño Martínez, Jesús María (1962), Contribución al estudio del gótico en Galicia, Valladolid, Universidad de Valladolid. 
Caamaño Martínez, Jesús María (1991), Pervivencia y ecos del Pórtico de la Gloria en el gótico gallego, en Actas del Simposio Internacional sobre O Pórtico da Gloria e a Arte do seu Tempo, Santiago, Xunta de Galicia, pp. 439-456.

Caamaño Martínez, Jesús María (1999), La iglesia de San Martín de Noya, en Mostra Filatélica Internacional, Noia, Grupo Filatélico y Numismático, pp. 37-39.

Caamaño Martínez, Jesús María (2005), San Bartolomé v.s./ San Martín, en Mostra Filatélica, Noia, Grupo Filatélico y Numismático, pp. 73-77.

Carré Aldao, Eugenio (1928), Provincia de La Coruña, en Carreras Candi, Francesc (dir.), Geografía General del Reino de Galicia, vol. VI, Barcelona, Alberto Martín.

Carrero Santamaría, Eduardo (1999), La funcionalidad espacial en la arquitectura del medievo y las dependencias catedralicias como objeto del estudio histórico-artístico, "Medievalismo" 9, pp. 149-175.

Carrero Santamaría, Eduardo (2011), Cathédrale et topographie funéraire dans l'architecture médiévale de la Péninsule Ibérique, "Les Cahiers de Saint-Michel de Cuxa" 42, pp. 115-129.

Castelli, Patricia (1995), Dalla conchiglia di venere alla conchiglia di Sant'Iacopo. La metamorfosi di un símbolo, en Carro Otero, José (coord.), Actas del Congreso de Estudios Jacobeos, Santiago de Compostela, Xunta de Galicia, pp. 109-134.

Cendón Fernández, Marta (1995), El sepulcro del arzobispo don Álvaro de Isorna en la catedral de Santiago, "Cuadernos de Estudios Gallegos" 42/107, pp. 209-226.

Cendón Fernández, Marta (1996), Iconografía funeraria del obispo en la Castilla de los Trastámara, Santiago de Compostela, Universidad de Santiago de Compostela (tesis doctoral).

Cendón Fernández, Marta (2003), Aspectos iconográficos del sepulcro del Arzobispo Diego de Anaya, "Boletín del Museo e Instituto de Humanidades Camón Aznar" 90, pp. 39-54.

Cendón Fernández, Marta (2017), Iconografía mariana en la Compostela medieval, en Rucquoi, Adeline (ed.), María y Iacobus en los Caminos Jacobeos, Santiago de Compostela, Xunta de Galicia, pp. 443-484.

Cendón Fernández, Marta; Barral Rivadulla, Dolores (1999), Donantes y promotores: su imagen en la plástica gótica gallega, "Semata" 10, pp. 389-418.

Cendón Fernández, Marta; Barral Rivadulla, Dolores; Fraga Sampedro, Dolores (2000), Arte y poder en la Galicia de los Trastámara: la provincia de La Coruña, Santiago de Compostela, Tórculo. 
Cendón Fernández, Marta; Chao Castro, David (2014), Las catedrales gallegas al final del medievo, en Alonso, Begoña; Villaseñor, Fernando (eds.) Arquitectura tardogótica en la Corona de Castilla: trayectorias e intercambios, Santander - Sevilla, Universidad de Cantabria - Universidad de Sevilla, pp. 55-84.

Escandell Proust, Isabel Juana; Boto Varela, Gerardo; Lozano, Esther (eds.) (2019), The Memory of the Bishop in Medieval Cathedrals: Ceremonies and Visualizations, Berna, Peter Lang.

Español Bertrán, Francesca (2015), Encuadres arquitectónicos para la muerte: de lo ornamental a lo representativo. Una aproximación a los proyectos funerarios del tardogótico hispano, "Codex Aquilarensis" 31, pp. 93-120.

Fabeiro Gómez, Manuel; Fernández Oxea, José Ramón (2001), Escudos de Noia, en Mostra Historia Postal de Galicia, Noia, Grupo Filatélico y Numismático, pp. 1-83.

Faginas Arcuaz, Ramón (1884), San Martín de Noya, "La Ilustración Española y Americana" 28/12, pp. 205-206.

Fandiño Fuentes, Rafael (2019), Reliquias y relicarios medievales en la catedral de Santiago de Compostela. Origen y evolución, Santiago de Compostela, Universidad de Santiago (tesis doctoral).

Fernández González, Alberto (2005), La desaparecida capilla de Don Lope de Mendoza: nuevos datos sobre sus retablos, los sepulcros, su coro alto y la sacristia, "Cuadernos de estudios gallegos" 52/118, pp. 347-385.

Fernández Rodríguez, Begoña (1998), El patronato artístico de las cofradías de mareantes en Galicia. Siglos XV-XVI, Santiago de Compostela, Universidad de Santiago (tesis doctoral).

Fernández Rodríguez, Begoña (1999), El colegio apostólico en la Baja Edad Media: el ejemplo de la fachada occidental de San Martiño de Noia, en Mostra Filatélica Internacional, Noia, Grupo Filatélico y Numismático, pp. 41-50.

Fernández Rodríguez, Begoña (2000a), La inmortalización del legado de don Lope de Mendoza en Noia. La portada norte de San Martiño, en Mostra Filatélica Nacional, Noia, Grupo Filatélico y Numismático, pp. 81-88.

Fernández Rodríguez, Begoña (2000b), Un ejemplo de periodización: el templo de San Martiño de Noia, "Cuadernos de Estudios Gallegos" 47/112, pp. 227-247.

Fernández Rodríguez, Begoña (2002), Reflexiones sobre la parroquial de San Martiño de Noia: aproximación a un conjunto arquitectónico gótico, en Mostra Filatélica, Noia, Grupo Filatélico y Numismático, pp. 51-59. 
Ferrando Roig, Juan (1950), Iconografía de los santos, Barcelona, Omega.

Ferreira Priegue, Elisa (1988), Galicia en el comercio marítimo medieval, La Coruña, Fundación Pedro Barrié de la Maza.

Figueiredo, Paula; Noé, Paula (2004-2005), Igreja Parroquial de Viana do Castelo / Catedral de Viana do Castelo, SIPA [en línea], http://www. monumentos.gov.pt/Site/APP_PagesUser/SIPA.aspx?id=4129 [consulta: 20/04/2020].

Flórez, Henrique (1764), España Sagrada, vol. XVIII, Madrid, Oficina de Antonio Marín.

García Oro, José (1987), Galicia en los siglos XIV y XV, La Coruña, Fundación Pedro Barrié de la Maza.

García Vidal, Pedro (1991), A Noia da memoria: pasado e presente dun casco histórico, Vigo, Concello de Noia.

Gonçalves, Flávio (1961), O Pórtico da Matriz de Viana do Castelo, "MVSEV" 3/2, pp. 60-71.

González Dávila, Gil (1645), Teatro eclesiástico de las iglesias metropolitanas y catedrales de los reinos de las dos Castillas. Vidas de sus arzobispos y obispos y cosas memorables de sus sedes, vol. I, Madrid, Imprenta de Francisco Martínez.

Herráez, M. ${ }^{\mathrm{a}}$ Victoria; Cosmen, M. ${ }^{\mathrm{a}}$ Concepción; Teijeira, M. ${ }^{\mathrm{a}}$ Dolores; Moráis Morán, José A. (eds.) (2018), Obispos y Catedrales. Arte en la Castilla bajomedieval, Berna, Peter Lang.

Hoyo, Jerónimo del (1952), Memorias del Arzobispado de Santiago, Santiago, Porto.

Iglesias Almeida, Ernesto (2008), O antigo bispado de Tui en Portugal, Noia, Toxosoutos.

López Alsina, Fernando (1999), Años Santos Romanos y Años Santos Compostelanos, en Caucci, Paolo (ed.), Santiago, Roma, Jerusalén. Actas del III Congreso de Estudios Jacobeos, Santiago de Compostela, Xunta de Galicia, pp. 213-242.

López Ferreiro, Antonio (1895), Fueros municipales de Santiago y de su Tierra, Santiago de Compostela, Imp. y enc. del Seminario C. Central.

López Ferreiro, Antonio (1901), Historia de la S.A.M.I. de Santiago de Compostela, vol. IV, Santiago de Compostela, Imp. y enc. del Seminario Conciliar Central.

López Ferreiro, Antonio (1904), Historia de la S.A.M.I. de Santiago de Compostela, vol. VII, Santiago de Compostela, Imp. y enc. del Seminario Conciliar Central.

López García, Atanasio (1914), Memorias históricas de la Provincia de Santiago, "El Eco Franciscano" 31, pp. 13-14, 37-41, 71-74, 225-229, 376-377, 498-500. 
Manso Porto, Carmen (1993), Arte gótico en Galicia: los dominicos, La Coruña, Fundación Pedro Barrié de la Maza.

Martínez Murguía, Manuel (1888), Galicia. España: sus monumentos y artes, su naturaleza e historia, Barcelona, Establecimiento Tipográfico Daniel Cortezo y $\mathrm{C}^{\mathrm{ia}}$.

Miraz Seco, María Violeta (2013), La peregrinación marítima. El camino inglés desde la ría de Ferrol en la Baja Edad Media, Ferrol, Universidade de A Coruña (tesis doctoral).

Moralejo Álvarez, Serafín (1993), Báculo de Santa Isabel de Portugal, en Santiago, camino de Europa. Culto y cultura en la peregrinación a Compostela, Santiago de Compostela, Xunta de Galicia, ficha n. ${ }^{\circ} 126$, pp. 434-435.

Nogueira Santiago, Paulo (2017), Noia e a súa historia, Noia, Toxosoutos.

Ortiz de Zúñiga, Diego (1795), Anales eclesiásticos y seculares de la muy noble y muy leal ciudad de Sevilla, vol. II, Madrid, Imprenta Real.

Pardo de Guevara y Valdés, Eduardo (2012), De la aparición y primer desarrollo de las armerías en Galicia. Noticias, testimonios y comentarios, en De linajes, parentelas y grupos de poder. Aportaciones a la historia social de la nobleza bajomedieval gallega, Madrid, Fundación cultural de la nobleza española - CSIC.

Ramos Campos, Leandro (2018), Estudo Monográfico de Monumentos do Centro Histórico de Viana do Castelo, Porto, Universidade do Porto (tesis de maestría).

Réau, Louis (1998), Iconografía del arte cristiano, Barcelona, Ediciones del Serbal. Rodríguez González, Ángel (ed.) (1994), O tumbo vermello de don Lope de Mendoza, Santiago de Compostela, CSIC - Instituto de Estudios Gallegos "Padre Sarmiento" (Cuadernos de Estudios Gallegos, anexo XXIII).

Taín Guzmán, Miguel (2019), La ciudad de Santiago de Compostela según los hermanos Juan y Pedro Fernández de Boán (ca.1633-1646), Santiago de Compostela, Teófilo Edicións - Consorcio de Santiago.

Teijeira, M. ${ }^{\text {a }}$ Dolores; Herráez, M. ${ }^{\text {a }}$ Victoria; Cosmen, M. ${ }^{\text {a }}$ Concepción (eds.) (2014), Reyes y prelados. La creación artística en los reinos de León y Castilla (1050-1500), Madrid, Sílex.

Vázquez Castro, Julio (2009), Castillos en el aire: el inicio del cimborrio gótico de la catedral compostelana, "Quintana" 8, pp. 245-269.

Vázquez de Parga, Luis; Lacarra, José María; Uría Riu, Juan (1948), Las peregrinaciones a Santiago de Compostela, vol. I, Pamplona, Iberdrola - Gobierno de Navarra, 1992.

Vilarinho Rocha Lourenço, Maria Natália (2014), A vida e a obra do historiador Flávio Gonçalves (1929-1987). Estudos breves, Lisboa, Universidade Aberta - Mestrado em Estudos do Património. 
Yarza Luaces, Joaquín (1988), La capilla funeraria hispana en torno a 1400, en Núñez Rodríguez, Manuel; Portela Silva, Ermelindo (coords.), La idea y el sentimiento de la muerte en la Historia y en el Arte de la Edad Media, Santiago de Compostela, USC, pp. 67-91.

Yzquierdo Perrín, Ramón (2006-2007), El mecenazgo del arzobispo compostelano don Lope de Mendoza en Santiago y Padrón, "Abrente" 3839, pp. 117-172.

Yzquierdo Perrín, Ramón; Manso Porto, Carmen (1996), Arte medieval (II). Galicia. Arte, vol. XI, La Coruña, Hércules.

Fecha de recepción del artículo: julio 2020

Fecha de aceptación y versión final: marzo 2021 